\title{
Online Appendix Gift Exchange versus Monetary Exchange: Theory and Evidence
}

\author{
John Duffy Daniela Puzzello*
}

\section{Appendix A: Theoretical Predictions}

\section{Lagos-Wright Environment}

Let $\left(m^{1}, m^{2}, \ldots, m^{2 N}\right)$ denote the initial distribution of money holdings, where $m^{i}$ denotes the money holdings of agent $i$. We denote by $m_{t}^{i}$ the money holdings of agent $i$ at the beginning of period $t$.

Since the total money stock is fixed at $M$, we clearly have $\sum_{i=1}^{2 N} m_{t}^{i}=M$ for all periods $t=1,2, \ldots$. Let $\phi_{t}$ denote the price of money in terms of the general good in the centralized meeting. Also, let $\varphi: A \rightarrow A$ be an exhaustive bilateral matching rule, so that no agent remains unmatched. ${ }^{1}$

In the first subperiod (decentralized meeting), agents are randomly (uniformly) and bilaterally matched and an agent is randomly chosen to be the producer or the consumer in his match with equal probability. Each consumer proposes terms of trade and the producers' choice variable is to accept or reject the proposed terms of trade.

In the second subperiod (centralized meeting) agents decide on consumption and production of the general good and on their savings (or equivalently how much money to carry over to the next decentralized meeting subperiod). That is, they decide how much to sell or buy in the Walrasian market in order to rebalance their money holdings.

We denote by $V_{t}\left(m_{t}^{i}\right)$ the value function for an agent with $m_{t}^{i}$ money holdings at the beginning of the decentralized meeting in period $t$. In a bilateral match where the consumer has $m$ money holdings and the producer has $\widetilde{m}$ money holdings, $q_{t}(m, \widetilde{m})$ and $d_{t}(m, \widetilde{m})$ denote the terms of trade, i.e., the amount of special good produced and the amount of money the consumer pays, respectively. We denote by $X_{t}, Y_{t}$ and $m_{t+1}^{i}$ consumption of the general good, production of the general good and savings, respectively.

${ }^{*}$ Duffy: Department of Economics, University of California, Irvine, 3151 Social Science Plaza, Irvine CA 92697; Puzzello: Department of Economics, Indiana University, 100 S. Woodlawn Ave., Bloomington, IN 47405 .

${ }^{1}$ An exhaustive bilateral matching rule is simply a function $\varphi: A \rightarrow A$ such that $\varphi(\varphi(a))=a$ and $\varphi(a) \neq a$, for all $a \in A$. See also Aliprantis, Camera, and Puzzello, "ACP" (2007ab). 
Then

$$
\begin{aligned}
& V_{t}\left(m_{t}^{i}\right)=\underset{X_{t}, Y_{t}, m_{t+1}^{i}}{\operatorname{Max}}\left\{\frac { 1 } { 2 } \sum _ { j \neq i } \left[u\left(q_{t}\left(m_{t}^{i}, m_{t}^{j}\right)+X_{t}^{c}-Y_{t}^{c}+\beta V_{t+1}\left(m_{t+1}^{i}\right)\right] \operatorname{Pr}(\varphi(i)=j)\right.\right. \\
& +\frac{1}{2} \sum_{j \neq i}\left[-c\left(q_{t}\left(m_{t}^{j}, m_{t}^{i}\right)+X_{t}^{p}-Y_{t}^{p}+\beta V_{t+1}\left(m_{t+1}^{i}\right)\right] \operatorname{Pr}(\varphi(i)=j)\right\},
\end{aligned}
$$

subject to the budget constraints associated with the centralized meeting:

$$
\begin{aligned}
& X_{t}^{c}=Y_{t}^{c}+\phi_{t}\left(m_{t}^{i}-d_{t}\left(m_{t}^{i}, m_{t}^{j}\right)-m_{t+1}^{i}\right), \\
& X_{t}^{p}=Y_{t}^{p}+\phi_{t}\left(m_{t}^{i}+d_{t}\left(m_{t}^{j}, m_{t}^{i}\right)-m_{t+1}^{i}\right), \\
& X_{t}^{c}, X_{t}^{p}, Y_{t}^{c}, Y_{t}^{p}, m_{t+1}^{i} \geq 0 .
\end{aligned}
$$

The terms in $V_{t}\left(m_{t}^{i}\right)$ represent the expected payoff from being a consumer or a producer. After substituting in the budget constraints, it is easy to see that $V_{t}\left(m_{t}^{i}\right)$ can be simplified as follows:

$$
\begin{aligned}
& V_{t}\left(m_{t}^{i}\right)=\left\{\frac { 1 } { 2 } \sum _ { j \neq i } \left[u\left(q_{t}\left(m_{t}^{i}, m_{t}^{j}\right)-\phi_{t} d_{t}\left(m_{t}^{i}, m_{t}^{j}\right)\right] \operatorname{Pr}(\varphi(i)=j)\right.\right. \\
& \left.+\frac{1}{2} \sum_{j \neq i}\left[-c\left(q_{t}\left(m_{t}^{j}, m_{t}^{i}\right)\right)+\phi_{t} d_{t}\left(m_{t}^{j}, m_{t}^{i}\right)\right] \operatorname{Pr}(\varphi(i)=j)\right\}+\phi_{t} m_{t}^{i} \\
& +\underset{m_{t+1}^{i}}{\operatorname{Max}}\left\{-\phi_{t} m_{t+1}^{i}+\beta V_{t+1}\left(m_{t+1}^{i}\right)\right\} .
\end{aligned}
$$

We can now determine the terms of trade in the decentralized meeting, which will allow us to further simplify the expression for $V_{t}\left(m_{t}^{i}\right)$. As in Lagos and Wright (2005), we use the generalized Nash bargaining solution where threat points are given by continuation values. Here, we focus on take-it-or-leave-it offers where the consumer has all of the bargaining power. ${ }^{2}$ Thus, given the linearity, the terms of trade $\left(q_{t}, d_{t}\right)$ must solve the following constrained optimization problem:

$$
\begin{aligned}
& \underset{q_{t}, d_{t}}{\operatorname{Max}}\left[u\left(q_{t}\right)-\phi_{t} d_{t}\right] \\
& \text { s.t. } d_{t} \leq m_{t}, q_{t} \geq 0
\end{aligned}
$$

The solution to this optimization problem is given by:

$$
\begin{aligned}
& q_{t}\left(m_{t}, \tilde{m}_{t}\right)=q_{t}\left(m_{t}\right)= \begin{cases}c^{-1}\left(\phi_{t} m_{t}\right) & \text { if } m_{t}<\frac{c\left(q^{*}\right)}{\phi_{t}} \\
q^{*} & \text { if } m_{t} \geq \frac{c\left(q^{*}\right)}{\phi_{t}}\end{cases} \\
& d_{t}\left(m_{t}, \widetilde{m}_{t}\right)=d_{t}\left(m_{t}\right)=\left\{\begin{array}{lll}
m_{t} & \text { if } & m_{t}<\frac{c\left(q^{*}\right)}{\phi_{t}} \\
\frac{c\left(q^{*}\right)}{\phi_{t}} & \text { if } & m_{t} \geq \frac{c\left(q^{*}\right)}{\phi_{t}}
\end{array}\right.
\end{aligned}
$$

\footnotetext{
${ }^{2}$ Note that the take-it-or-leave-it offer implies higher allocative efficiency among the class of Nash bargaining trading protocols.
} 
That is, if the consumer carries over to the decentralized meeting at least $\frac{c\left(q^{*}\right)}{\phi_{t}}$ money holdings, then he gets $q^{*}$ in exchange for $\frac{c\left(q^{*}\right)}{\phi_{t}}$. If his money holdings are less than $\frac{c\left(q^{*}\right)}{\phi_{t}}$, then he is cash-constrained and he spends all his money holdings to buy $c^{-1}\left(\phi_{t} m_{t}\right)$ of the special good.

Next, note that the terms of trade depend only on the consumer's money holdings and $-c\left(q_{t}\left(m_{t}, \widetilde{m}_{t}\right)\right)+\phi_{t} d_{t}\left(m_{t}, \widetilde{m}_{t}\right)=0$. This allows us to further simplify the value function:

$$
\begin{aligned}
& V_{t}\left(m_{t}^{i}\right)=\frac{1}{2}\left[u\left(q_{t}\left(m_{t}^{i}\right)-\phi_{t} d_{t}\left(m_{t}^{i}\right)\right]\right. \\
& +\phi_{t} m_{t}^{i}+\underset{m_{t+1}^{i}}{\operatorname{Max}}\left\{-\phi_{t} m_{t+1}^{i}+\beta V_{t+1}\left(m_{t+1}^{i}\right)\right\} .
\end{aligned}
$$

By repeated substitution, we obtain that the amount of money carried over from the centralized to the decentralized meeting (or savings), $m_{t+1}^{i}$, solves a sequence of simple static optimization problems:

$$
\underset{m_{t+1}^{i}}{\operatorname{Max}}\left\{-\left(\phi_{t}-\beta \phi_{t+1}\right) m_{t+1}^{i}+\beta \frac{1}{2}\left[u\left(q_{t+1}\left(m_{t+1}^{i}\right)-\phi_{t+1} d_{t+1}\left(m_{t+1}^{i}\right)\right]\right\} .\right.
$$

This savings choice is governed by trading off the benefit (the liquidity return to money) given by $\beta \frac{1}{2}\left[u\left(q_{t+1}\left(m_{t+1}^{i}\right)-\phi_{t+1} d_{t+1}\left(m_{t+1}^{i}\right)\right]\right.$ with the cost of holding money $-\left(\phi_{t}-\beta \phi_{t+1}\right) m_{t+1}^{i}$ associated with delayed consumption. Any equilibrium must satisfy $\phi_{t} \geq \beta \phi_{t+1}$. Furthermore, the assumptions on the utility and cost functions imply that the solution is unique and thus the distribution of money holdings is degenerate at $\frac{M}{2 N}$.

A monetary equilibrium is any path $\left\{q_{t}\right\}_{t=1}^{\infty}$ with $q_{t} \in\left(0, q^{*}\right)$ such that

$$
\frac{u^{\prime}\left(q_{t+1}\right)}{c^{\prime}\left(q_{t+1}\right)}=1+\frac{\frac{c\left(q_{t}\right)}{c\left(q_{t+1}\right)}-\beta}{\frac{\beta}{2}} .
$$

Furthermore, the steady state (or stationary equilibrium) is unique, and the steady state condition is given by

$$
\frac{u^{\prime}(\widetilde{q})}{c^{\prime}(\widetilde{q})}=1+\frac{1-\beta}{\frac{\beta}{2}} .
$$

Each individual's demand for money is $M^{D}=\frac{c(\widetilde{q})}{\phi}$. The aggregate demand for money is therefore $2 N \frac{c(\widetilde{q})}{\phi}$, and since the money supply is equal to $M$, the equilibrium price of money in the steady state is $\phi=\frac{c(\widetilde{q})}{\frac{M}{2 N}}$. Note that $\widetilde{q}<q^{*}$ since $\beta<1$, and that $\widetilde{q} \rightarrow q^{*}$ as $\beta \rightarrow 1$. Also, the monetary steady state value function is given by

$$
V=\frac{1}{1-\beta}\left\{\frac{1}{2}[u(\widetilde{q})-c(\widetilde{q})]\right\} .
$$

\section{Social Norms in the Lagos-Wright Environment}

Under our parameterization choice, the first best can be supported as a sequential equilibrium under the decentralized social norm. In particular, conditions (1) and (2) in the paper are satisfied for $q^{*}=6$ when $2 N=6$ and $2 N=14$, respectively: 
I. $2 N=6$

Condition (1) simplifies to:

$$
\begin{gathered}
-q^{*}+\frac{\beta}{1-\beta} \frac{1}{2}\left[u\left(q^{*}\right)-q^{*}\right] \geq e_{1}[I-\beta A]^{-1} \pi \frac{1}{2} u\left(q^{*}\right)-\frac{1}{2} u\left(q^{*}\right), \text { or } \\
-6+5 \frac{1}{2}[7 \ln 7-6] \geq 2.12 * \frac{1}{2} 7 \ln 7-\frac{1}{2} 7 \ln 7, \text { or } \\
13.053 \geq 2.12 * 6.81-6.81, \text { or } \\
13.053 \geq 7.627 .
\end{gathered}
$$

Condition (2) simplifies to:

$$
\begin{aligned}
&-q^{*}+e_{2}[I-\beta A]^{-1} \pi \frac{1}{2} u\left(q^{*}\right)-\left(\frac{2 N-2}{2 N-1}\right) \frac{1}{2} u\left(q^{*}\right) \leq e_{3}[I-\beta A]^{-1} \pi \frac{1}{2} u\left(q^{*}\right)-\left(\frac{2 N-3}{2 N-1}\right) \frac{1}{2} u\left(q^{*}\right), \text { or } \\
&-6+1.344 * 6.81-\frac{4}{5} * 6.81 \leq 0.84 * 6.81-\frac{3}{5} 6.81, \text { or } \\
&-3.9298 \leq 0 .
\end{aligned}
$$

II. $2 N=14$

Condition (1) simplifies to:

$$
\begin{gathered}
-q^{*}+\frac{\beta}{1-\beta} \frac{1}{2}\left[u\left(q^{*}\right)-q^{*}\right] \geq e_{1}[I-\beta A]^{-1} \pi \frac{1}{2} u\left(q^{*}\right)-\frac{1}{2} u\left(q^{*}\right), \text { or } \\
-6+5 \frac{1}{2}[7 \ln 7-6] \geq 2.798 * \frac{1}{2} 7 \ln 7-\frac{1}{2} 7 \ln 7, \text { or } \\
-6+5 \frac{1}{2} 7.6214 \geq 1.798 \frac{1}{2} 7 \ln 7, \text { or }
\end{gathered}
$$

$$
13.053 \geq 12.246
$$

Condition (2) simplifies to:

$$
\begin{gathered}
-q^{*}+e_{2}[I-\beta A]^{-1} \pi \frac{1}{2} u\left(q^{*}\right)-\left(\frac{2 N-2}{2 N-1}\right) \frac{1}{2} u\left(q^{*}\right) \leq e_{3}[I-\beta A]^{-1} \pi \frac{1}{2} u\left(q^{*}\right)-\left(\frac{2 N-3}{2 N-1}\right) \frac{1}{2} u\left(q^{*}\right), \text { or } \\
-6+2.158 * 6.81-\left(\frac{12}{13}\right) 6.81 \leq 1.739 * 6.81-\left(\frac{11}{13}\right) 6.81, \text { or } \\
-6+14.69-6.2862 \leq 11.843-5.762, \text { or }
\end{gathered}
$$




$$
\begin{gathered}
2.403 \leq 6.081, \text { or } \\
-3.678 \leq 0 .
\end{gathered}
$$

The largest population size under which both conditions (1) and (2) are satisfied is $2 N=16$. We did not pick the largest population size compatible with these conditions. Instead, we chose as our upper bound the next largest population size, namely $2 N=14$, which we consider a more appropriate choice, as it is avoids the case where conditions (1) and (2) are barely satisfied by the chosen parameters.

Similar computations were conducted to find the lowest quantity $q$, that satisfies these inequalities and these are reported in Tables 1 and 17 of the paper.

\section{Centralized Social Norms in the No Money Environment}

Here we report the computations used to find the equilibrium range of values for $q$, as reported in Table 1 of the paper. We used equations (3) and (4) of the paper. Observe that if $c(q) \geq L / 2 N, \operatorname{Max}\{\underline{\beta}, \underline{\beta}\}=\underline{\beta}=\frac{\frac{2 N-2}{2 N} L+c(q)}{\frac{2 N-2}{2 N} L+c(q)+\frac{1}{2}[u(q)-c(q)]}$, while if $c(q)<L / 2 N, \operatorname{Max}\{\underline{\beta}, \underline{\beta}\}=$ $\underline{\beta}=\frac{\frac{2 N-1}{2 N} L}{\frac{2 N-1}{2 N} L+\frac{1}{2}[u(q)-c(q)]}$.

Given our parameterization with $L=1$, we then have the following:

I. $2 N=6$

If $q \geq 1 / 6, \operatorname{Max}\{\underline{\beta}, \underline{\beta}\}=\underline{\beta}=\frac{\frac{4}{6}+q}{\frac{4}{6}+q+\frac{1}{2}[7 \ln (1+q)-q]}$. It is easy to check that $\underline{\beta} \leq \frac{5}{6}$ is always satisfied for $q \geq 1 / 6$.

If $q<1 / 6, \operatorname{Max}\{\underline{\beta}, \underline{\underline{\beta}}\}=\underline{\underline{\beta}}=\frac{\frac{5}{6}}{\frac{5}{6}+\frac{1}{2}[7 \ln (1+q)-q]}$. It is easy to check that $\underline{\underline{\beta}} \leq \frac{5}{6}$ is satisfied for $q \geq 0.058$.

Thus, given $\beta=\frac{5}{6}$, any $q \in[0.058,6]$ can be supported as a sequential equilibrium for $2 N=6$.

II. $2 N=14$

If $q \geq 1 / 14 \approx 0.072, \operatorname{Max}\{\underline{\beta}, \underline{\beta}\}=\underline{\beta}=\frac{\frac{12}{14}+q}{\frac{12}{14}+q+\frac{1}{2}[7 \ln (1+q)-q]}$. It is easy to check that $\underline{\beta} \leq \frac{5}{6}$ is always satisfied for $q \geq 1 / 14$.

If $q<1 / 14, \operatorname{Max}\{\underline{\beta}, \underline{\underline{\beta}}\}=\underline{\underline{\beta}}=\frac{\frac{13}{14}}{\frac{13}{14}+\frac{1}{2}[7 \ln (1+q)-q]}$. It is easy to check that $\underline{\underline{\beta}} \leq \frac{5}{6}$ is never satisfied for $q<1 / 14$.

Thus, given $\beta=\frac{5}{6}$ any $q \in[0.072,6]$ can be supported as a sequential equilibrium for $2 N=14$.

\section{Theoretical Predictions in Environments with a Trading Post}

This section provides details for the theoretical predictions associated with the environments where trade in the centralized meeting is arranged via a trading post as in our modified experimental design. 


\section{Sequential Equilibrium Outcomes in the Environment with a Trading Post and No Money}

We represent strategy profiles by means of automata, as they allow to us to group histories into equivalence classes associated with the states of the automata therefore allowing us to discuss strategies in a more compact way. Furthermore, it is possible to show that automata induce strategies and, conversely, any strategy profile can be represented by an automaton (see Mailath and Samuelson (2006) for a discussion of automaton representations of strategy profiles).

Next we show that there exists an equilibrium that sustains positive production and consumption (including the first-best) if agents are sufficiently patient. Let $0<q \leq q^{*}$. We can define as $\{$ yes, no\} the action sets of agents in the decentralized meeting, where yes is identified with accepting a proposal of amount $q$. If both agents in a meeting say yes, $q$ is produced and consumed. If at least one agent says no, then no production or consumption takes place in that meeting. The action set in the centralized meeting consists of the set $\left\{(y, b) \in[0, \bar{Y}]^{2}: b \leq y\right\}$. Define $\sigma^{*}$ to be the strategy profile in which an agent behaves according to the following automaton. The set of states is $W=\{C, D, A\}$ and the initial state is $C$. Intuitively, $C$ stands for cooperation, $D$ for defection, and $A$ for autarky. The decision rules for decentralized and centralized meetings are given by

$$
f_{1}(w)=\left\{\begin{array}{ll}
\text { yes } & \text { if } w \in\{C, D\} \\
\text { no } & \text { if } w=A
\end{array} \text { and } f_{2}(w)=\left\{\begin{array}{lll}
(x, x) & \text { if } w=C \\
(x, 0) & \text { if } w=D \\
(0,0) & \text { if } w=A
\end{array}\right.\right.
$$

where $0<x \leq \bar{Y}$. For instance, an agent in state $C$ behaves as follows. In the decentralized meeting, he agrees to trade. In the centralized meeting he contributes production $x$ to the trading post and then bids for amount $x$ at the trading post. The transition rules are given by

$$
\tau_{1}\left(w, a_{1}, a_{1}^{\prime}\right)=\left\{\begin{array}{lll}
C & \text { if } & w=C \text { and }\left(a_{1}, a_{1}^{\prime}\right)=(\text { yes, yes }) \\
D & \text { if } w=C \text { and }\left(a_{1}, a_{1}^{\prime}\right) \neq(\text { yes, yes }) \\
w & \text { if } w \in\{D, A\}
\end{array}\right.
$$

and

$$
\tau_{2}\left(w, a_{2}, p\right)=\left\{\begin{array}{lll}
C & \text { if } \quad w \in\{C, D\} \text { and } p \in\left\{1, \frac{N-2}{N}\right\} \\
A & \text { if } \quad w \in\{C, D\} \text { and } p \notin\left\{1, \frac{N-2}{N}\right\} \text { or } w=A
\end{array},\right.
$$

where $p^{D}=\frac{(N-2)}{N}$ is the price vector in the centralized meeting when $(N-2)$ agents are in state $C$ and the two remaining agents are in state $D$. For instance, an agent in state $C$ in the decentralized meeting remains in state $C$ only if trade takes place in his match, otherwise he moves to state $D$. Likewise, an agent in state $C$ in the centralized meeting stays in $C$ if the price he observes belongs to $\left\{1, \frac{N-2}{N}\right\}$, otherwise he moves to state $A$.

Let $V_{D M}^{*}$ and $V_{C M}^{*}$ denote the equilibrium value functions (associated with $q>0$ ) at the beginning of the decentralized and centralized meetings, respectively. Then

$$
V_{D M}^{*}=\frac{1}{1-\beta} \frac{1}{2}(u(q)-c(q)) \text { and } V_{C M}^{*}=\frac{\beta}{1-\beta} \frac{1}{2}(u(q)-c(q))=\beta V_{D M}^{*} .
$$


Let $V_{C M}^{D}$ denote the (off-equilibrium) value function at the beginning of the centralized meeting when the state is $D$. Then

$$
V_{C M}^{D}=-x+\beta V_{D M}^{*}
$$

Note also that in the autarkic state, $V_{C M}^{A}=V_{D M}^{A}=0$.

Now let $\mu^{*}$ be the belief system such that: $(i)$ an agent in state $C$ believes that all other agents are in state $C ;(i i)$ an agent in state $A$ believes that all other agents are in state $A$; $(i i i)$ an agent in state $D$ believes that there exists one other agent in state $D$ and the remaining agents are in state $C$. Clearly, $\left(\sigma^{*}, \mu^{*}\right)$ is a consistent assessment and $\sigma^{*}$ implements the first-best. We have the following result.

Proposition 1 Let $q>0$ be a positive amount of production and consumption in the decentralized meeting. Suppose that $c(q) \leq x$, where $0<x \leq \bar{Y}$. Then there exists a $\delta^{\prime} \in(0,1)$ such that $\left(\sigma^{*}, \mu^{*}\right)$ is a sequential equilibrium for all $\delta \geq \delta^{\prime}$.

A sketch of the proof is as follows. Consider first an agent in state $C$ in the decentralized meeting. If he is a producer, his flow payoff gain from a one-shot deviation is $c(q)$. However, in the centralized meeting that immediately follows, he exerts effort $x$ and receives 0 . Since $c(q) \leq x$ by assumption, the one-shot deviation is not profitable.

Consider now an agent in state $C$ in the centralized meeting. First note that no oneshot deviation leading to $p \in\left\{1, \frac{N-2}{N}\right\}$ is profitable. Since any one-shot deviation with $p \notin\left\{1, \frac{N-2}{N}\right\}$ triggers permanent autarky, we can then conclude that no one-shot deviation is profitable if the agent is patient enough.

To sum up, on the equilibrium path, agents do not deviate from $\sigma^{*}$ in decentralized meetings since a deviation triggers a within-period punishment in the following centralized meeting (agents in state $D$ in the centralized meeting produce $x$ for the post and they get nothing since they bid 0), which in its turn is sustained by the threat of autarky. Similarly, a deviation in the centralized meeting would trigger autarkic behavior.

To finish, we need to show that behavior off the path of play is credible. It is immediate to see that no agent in state $A$ has an incentive to deviate. It is also immediate to see that no agent is ever in state $D$ in the decentralized meeting. Consider then an agent in state $D$ in the centralized meeting. First, it is possible to show that no one-shot deviation which leads to a price vector $p \in\left\{1, \frac{N-2}{N}\right\}$ is profitable. Since any one-shot deviation with $p \notin\left\{1, \frac{N-2}{N}\right\}$ triggers permanent autarky, we can then conclude that no one-shot deviation is profitable if agents are patient enough.

Thus no agent has an incentive to deviate from $\sigma^{*}$ off-the equilibrium path since either a deviation in the centralized meeting would trigger autarky or autarkic behavior is a best response to autarky.

\section{Proof of Proposition}

Let $V_{\mathrm{DM}}^{*}$ and $V_{\mathrm{CM}}^{*}$ be the (discounted) lifetime payoffs to an agent in state $C$ before he enters the decentralized and centralized meetings, respectively. Then,

$$
V_{\mathrm{DM}}^{*}=\frac{1}{1-\beta}\left\{\frac{1}{2}[u(q)-c(q)]\right\} \quad \text { and } \quad V_{\mathrm{CM}}^{*}=\beta V_{\mathrm{DM}}^{*} .
$$


Now let $V_{C M}^{A}$ and $V_{D M}^{A}$ be the lifetime payoffs to an agent in state $A$. It is easy to see that $V_{C M}^{A}=V_{D M}^{A}=0$. Finally, let $V_{C M}^{D}$ be the lifetime payoff to an agent in state $D$ before he enters the centralized meeting. Since an agent in state $D$ in the centralized meeting believes that there are $(N-2)$ agents in state $C$ and one other agent in state $D$, he believes that the price vector in the centralized meeting will be $\frac{N-2}{N}$. Thus,

$$
V_{C M}^{D}=-x+\frac{0}{\frac{N-2}{N}}+\beta V_{\mathrm{DM}}^{*}=-x+\beta V_{\mathrm{DM}}^{*} .
$$

We start with incentives in state $C$. An agent in state $C$ in the decentralized meeting has no profitable one-shot deviation if

$$
-c(q)+V_{\mathrm{CM}}^{*}=-c(q)+\beta V_{\mathrm{DM}}^{*} \geq-x+\beta V_{\mathrm{DM}}^{*},
$$

which is satisfied since $c(q) \leq x$. Consider then an agent in state $C$ in the centralized meeting. Let $a_{2}=(y, b) \neq(x, x)$ be the agent's action and denote the corresponding price by $p$. First, we show that there exists no profitable one-shot deviation by the agent when $a_{2}$ is such that $p=1$. It is immediate to see that $p=1$ if, and only if, $b=y$. Thus, when $a_{2} \neq(x, x)$ and $p=1$, the agent's flow payoff is 0 which is the same payoff he gets if he chooses $(x, x)$. Since $p=1$, the continuation payoff is the same. Therefore, there is no profitable one-shot deviation where $a_{2}$ is such that $p=1$. It is easy to check that a deviation where $a_{2}$ is such that $p=\frac{N-2}{N}$ is not profitable since it would lead to a lower flow payoff $\left(-\frac{2 x(N-1)}{N-2}<0\right)$ and the same continuation payoff. It is also easy to see that he has no profitable one-shot deviation when $a_{2}$ is such that $p \notin\left\{1, \frac{N-2}{N}\right\}$. In that case, an agent would get a lower flow payoff (since $b / p$ is increasing in $b$ ) and also a lower continuation payoff since he would trigger autarky. So there is no profitable one-shot deviation.

Next, consider incentives in state $D$. Given $\sigma^{*}$, an agent is never in state $D$ at the beginning of the decentralized meeting. Consider an agent in state $D$ in the centralized meeting. Let $a_{2}=(y, b) \neq(x, 0)$ be the agent's action and denote the corresponding price by $\widetilde{p}^{D}$. That is, $\widetilde{p}^{D}=\frac{(N-2) x+b}{(N-1) x+y}<1$. We need to consider two kinds of deviations: $\widetilde{p}^{D}=\frac{N-2}{N}$ or $\widetilde{p}^{D} \neq \frac{N-2}{N}$. In order for $\widetilde{p}^{D}=\frac{N-2}{N}$, it should be the case that $b=\frac{N-2}{N}(y-x)$. However, such a deviation would lead to the flow payoff since $\frac{b}{\frac{N-2}{N}}-y=-x<0$, which is not profitable. We next show that if agents are patient enough, a one-shot deviation with $\widetilde{p}^{D} \neq \frac{N-2}{N}$ is also not profitable. It is easy to check that $\frac{b}{\widetilde{p}^{D}}$ is increasing in $b$, therefore $b=y$. Given this, $\frac{y}{\widetilde{p}^{D}}=\frac{y}{\frac{(N-2) x+y}{(N-1) x+y}}$ is increasing in $y$, so the best deviation for an agent entails $b=y=\bar{Y}$. Furthermore, recall that $\widetilde{p}^{D} \neq \frac{N-2}{N}$ triggers autarky. Thus a one-shot deviation is not profitable if

$$
-x+\beta V_{\mathrm{DM}}^{*} \geq-\bar{Y}+\frac{\bar{Y}}{\frac{(N-2) x+\bar{Y}}{(N-1) x+\bar{Y}}}+0=\frac{x \bar{Y}}{(N-2) x+\bar{Y}} .
$$

That is, after substituting appropriately for the value functions,

$$
\beta \geq \frac{\frac{2 x \bar{Y}+(N-2) x^{2}}{(N-2) x+\bar{Y}}}{\frac{1}{2}[u(q)-c(q)]+\frac{2 x \bar{Y}+(N-2) x^{2}}{(N-2) x+\bar{Y}}} .
$$


To finish, since state $A$ is absorbing and involves no trade in both the decentralized and centralized meetings, it is immediate to see that no one-shot deviation is profitable in this state. We can then conclude that $\left(\sigma^{*}, \mu^{*}\right)$ is an equilibrium as long as

$$
\beta \geq \frac{\frac{2 x \bar{Y}+(N-2) x^{2}}{(N-2) x+\bar{Y}}}{\frac{1}{2}[u(q)-c(q)]+\frac{2 x \bar{Y}+(N-2) x^{2}}{(N-2) x+\bar{Y}}}=\underline{\beta} .
$$

This strategy is a modified version of the one proposed by Araujo et al. (2012) in the linear case. ${ }^{3}$ Given our parameterization, the strategy developed in Araujo et al. (2012) would not support the first best as a sequential equilibrium, since the strategy above would not be an equilibrium for $x=\bar{Y}$ (given $\beta=\frac{5}{6}$, expression 5 implies that the highest $x$ under which the strategy above supports the first best as a sequential equilibrium is $x=17.40$ ). The lowest discount factor under which positive amounts $q>0$ can be supported as sequential equilibria is increasing in $x$, which in turn should satisfy $x \geq c(q)$. Thus, the lowest discount factor under which a positive amount $q>0$ can be supported as a sequential equilibrium obtains when $x=c(q)$ or $x=q$, given our linearity assumption for $c(q)$. Thus, given our parameterization, the lowest discount factor under which the first best can be supported as a sequential equilibrium is obtained when $x=6$ and it is equal to $\beta_{14}^{C M}=0.66<\beta_{14}^{D M}=0.8256$.

Furthermore, since $\underline{\beta}=\frac{\frac{2 x \bar{Y}+(N-2) x^{2}}{(N-2) x \bar{Y}}}{\frac{1}{2}[u(q)-c(q)]+\frac{2 x \bar{Y}+(N-2) x^{2}}{(N-2) x+\bar{Y}}}$ is decreasing in $x=q$, under our parameterization, using de l'Hôpital's rule one can show that as $q \rightarrow 0$, we have $\beta \rightarrow 0.4$, and since $0.4<5 / 6$ any positive quantity $0<q \leq 6$ can be supported as a sequential equilibrium. ${ }^{4}$

\section{Monetary Equilibrium}

We focus on a modified version of the Lagos-Wright model where trade in the centralized meeting is arranged via a trading post. Time is discrete and denoted by $t=1,2, \ldots$. The centralized meeting is modeled as a single trading post where money is exchanged for the general good. Agents place bids in terms of fiat money. Each agent's bid cannot exceed his money holdings in the centralized meeting, i.e., for all agents $i$ and each period $t, 0 \leqslant b_{i t} \leqslant$ $m_{i t}^{C M}$.

Let $b_{i t}$ denote the bid of agent $i$ in period $t$ in terms of fiat money, and $y_{i t}$ the amount of the general good that agent $i$ produces for the trading post. When both the total money bids and the total good contributions are strictly positive, the price is given by $p_{t}=\sum \frac{\sum b_{j t}}{\sum y_{j t}}$. For all $i$, consumption in the centralized meeting is determined as follows:

$$
X_{i t}=\left\{\begin{array}{lll}
b_{i t} \frac{\sum y_{j t}}{\sum b_{j t}} & \text { if } & \sum y_{j t} \neq 0 \text { and } \sum b_{j t} \neq 0 \\
0 & \text { otherwise }
\end{array}\right.
$$

\footnotetext{
${ }^{3}$ The strategy discussed by Araujo at al. (2012), however, does not support the first best as a sequential equilibrium given our parameterization. Thus, we have modified it appropriately.

${ }^{4}$ We note that quantities higher than the first best can be supported as sequential equilibria, but we do not incorporate these in the analysis since they are not economically relevant.
} 
Money holdings are updated as follows

$$
m_{i t+1}^{D M}=\left\{\begin{array}{lll}
m_{i t}^{C M}+\frac{\sum b_{j t}}{\sum y_{j t}} y_{i t}-b_{i t} & \text { if } & \sum y_{j t} \neq 0 \text { and } \sum b_{j t} \neq 0 \\
m_{i t}^{C M} & \text { otherwise }
\end{array}\right.
$$

Note that the price formation mechanism guarantees that demand is equal to supply. The optimization problem in the centralized meeting can be written as follows:

$$
\begin{aligned}
W_{t}\left(m_{t}\right) & =\underset{b_{t}, m_{t+1}, y_{t}}{\operatorname{Max}}\left[U\left(\frac{b_{t}}{p_{t}}\right)-y_{t}+\beta V\left(m_{t+1}\right)\right] \\
\text { s.t. } m_{t+1} & =m_{t}+p_{t} y_{t}-b_{t}
\end{aligned}
$$

and, as the population grows large (or as agents act as price takers), we get the same solution as in Lagos and Wright (2005).

\section{References}

Aliprantis, Charalambos D., Gabriele Camera, and Daniela Puzzello. 2007a. "Contagion Equilibria in a Monetary Model." Econometrica 75 (1): 277-82.

Aliprantis, Charalambos D., Gabriele Camera, and Daniela Puzzello. 2007b. "Anonymous Markets and Monetary Trading." Journal of Monetary Economics 54 (7): 1905-28.

Araujo, Luis, Braz Camargo, Raoul Minetti, and Daniela Puzzello. 2012. "The Essentiality of Money in Environments with Centralized Trade." Journal of Monetary Economics 59 (7): 612-21.

Lagos, Ricardo, and Randall Wright. 2005. "A Unified Framework for Monetary Theory and Policy Analysis." Journal of Political Economy 113 (3): 463-84.

Mailath, George J., and Larry Samuelson. 2006. Repeated Games and Reputation: Long-Run Relationships. Oxford: Oxford University Press. 


\section{Appendix B: Additional Experimental Findings}

In the paper we reported on the main finding from our modified experimental design, Finding 9 that welfare is significantly higher in the environment with money than in the environments without it. In this appendix we report on some other findings using the data from our modified experimental design (sessions 18-27) as described in Table 16 of the paper. These results are organized as a number of different findings.

First, paralleling Finding 2 for the original design we have:

Finding 10 In the modified design, proposals are less likely to be accepted as the quantity requested increases. In the modified money treatment, proposals are more likely to be accepted the higher the number of tokens or the better the terms of trade offered.

Support for finding 10 comes from Table 21 which reports on a regression analysis similar to that reported in Table 4 for the original design. Under the modified design, both producers and consumers could accept offers depending on the round of bargaining reached up to a maximum of three rounds. Here we focus on the final decision made, either accept or reject, by either the consumer or the producer as a function of the final quantity $q$ and (in the money session) the final token amount $d$ that was "on the table" when a decision to reject or accept was made. The probit regression analysis as reported in Table 21 has dependent variables that are as described in the paper for Table 4. Note that the dummy variable M14 here refers to the four sessions of the modified design where there was money (sessions 18-21) and the new dummy variable NMNC, took on a value of 1 if there was no money and no centralized meeting stage as in sessions 26-27 and it was 0 otherwise.

Similar to the findings of Table 4, we find that the introduction of money leads to a significant increase in acceptance frequencies as indicated by the positive and significant coefficient on the dummy variable M14 in the first regression specification using data from all sessions of our modified experimental design. As in our first design, the likelihood that an offer is accepted is decreasing in the period number and in the final quantity proposed, $q$. In the money treatment sessions, proposals are more likely to be accepted the greater is the amount of tokens offered, $d$, or the greater terms of trade, $d / q$. Differently from the first experimental design we find that for our modified design, neither the grim nor the HLscore dummy variables are significant in any regression specification. We attribute this difference to the additional number of bargaining rounds that were present in our modified design.

Next, paralleling Finding 3 and Table 6 of the paper we report a regression analysis of some potential determinants of accepted offers in the decentralized meeting of our modified experimental design in Table 22. The variables are the same as in Table 6 except that we have added the dummy variable NMNC for the two no money sessions (26-27) that don't have a centralized meeting stage and we have also added the number of rounds of bargaining, "RoundsB" before an agreement was struck.

The main finding comes from the first column of Table 22 where we observe that the presence of money has a large impact on accepted quantities raising it from a baseline of 1.81 units to an additional 3.25 units for a sum of 5.06 units. This amount is eroded over time by the period number which largely accounts for the average quantity in the MM14 sessions being just 3.91. Notice however, that traded quantities are increasing (by a small 


\begin{tabular}{|c|c|c|c|c|}
\hline & \multicolumn{4}{|c|}{ Dependent Variable, Accept $=1$, Reject $=0$} \\
\hline & All Sessions & NM Sessions & M Sessions (1) & M Sessions (2) \\
\hline \multirow[t]{2}{*}{ Constant } & 0.466 & $1.817^{* * *}$ & 0.518 & $-0.437^{* * *}$ \\
\hline & $(0.486)$ & $(0.446)$ & $(0.338)$ & $(0.181)$ \\
\hline \multirow[t]{2}{*}{ NMNC } & -0.098 & $0.265^{*}$ & & \\
\hline & $(0.186)$ & $(0.147)$ & & \\
\hline \multirow[t]{2}{*}{ M14 } & $0.962^{* * *}$ & & & \\
\hline & $(0.378)$ & & & \\
\hline \multirow[t]{2}{*}{ NewSeq } & $0.345^{* * *}$ & $0.340^{*}$ & $0.567^{* * *}$ & $0.520^{* * *}$ \\
\hline & $(0.113)$ & $(0.182)$ & $(0.124)$ & $(0.113)$ \\
\hline \multirow[t]{2}{*}{ Period } & $-0.024^{* * *}$ & $-0.079^{* * *}$ & $-0.033^{*}$ & $-0.040^{*}$ \\
\hline & $(0.008)$ & $(0.010)$ & $(0.019)$ & $(0.025)$ \\
\hline \multirow[t]{2}{*}{ Grim } & 0.050 & 0.020 & 0.143 & 0.337 \\
\hline & $(0.139)$ & $(0.177)$ & $(0.221)$ & $(0.334)$ \\
\hline \multirow[t]{2}{*}{ HLscore } & -0.016 & -0.030 & 0.024 & 0.010 \\
\hline & $(0.063)$ & $(0.026)$ & $(0.034)$ & $(0.030)$ \\
\hline \multirow[t]{2}{*}{$q$} & $-0.167^{* *}$ & $-0.776^{* * *}$ & $-0.152^{* * *}$ & \\
\hline & $(0.077)$ & $(0.177)$ & $(0.045)$ & \\
\hline \multirow[t]{2}{*}{$d$} & & & $0.122^{* *}$ & \\
\hline & & & $(0.062)$ & \\
\hline \multirow[t]{2}{*}{$d / q$} & & & & $1.244^{* * *}$ \\
\hline & & & & $(0.253)$ \\
\hline \multirow[t]{2}{*}{$m_{p}$} & & & $0.015^{* * *}$ & $0.016^{* * *}$ \\
\hline & & & $(0.004)$ & $(0.005)$ \\
\hline \multirow[t]{2}{*}{$m_{c}$} & & & -0.008 & $-0.041^{*}$ \\
\hline & & & $(0.021)$ & $(0.027)$ \\
\hline No. obs. & 1,449 & 889 & 560 & 541 \\
\hline Log Likl. & -919.99 & -486.8 & -360.6 & -283.2 \\
\hline
\end{tabular}

Table 21: Probit Regression Analysis of Proposal Acceptance Decisions in the Modified Design 


\begin{tabular}{|c|c|c|}
\hline & All Sessions & M Sessions Only \\
\hline Dependent Variable: & $q$ & $d / q$ \\
\hline \multirow[t]{2}{*}{ Constant } & $1.815^{* * *}$ & $0.537^{*}$ \\
\hline & $(0.610)$ & $(0.316)$ \\
\hline \multirow[t]{2}{*}{ M14 } & $3.251^{* * *}$ & \\
\hline & $(0.278)$ & \\
\hline \multirow[t]{2}{*}{ NMNC } & $-0.189^{* *}$ & \\
\hline & $(0.090)$ & \\
\hline \multirow[t]{2}{*}{ NewSeq } & 0.283 & -0.039 \\
\hline & $(0.235)$ & $(0.052)$ \\
\hline \multirow[t]{2}{*}{ Period } & $-0.050^{* * *}$ & $0.032^{* * *}$ \\
\hline & $(0.007)$ & $(0.012)$ \\
\hline \multirow[t]{2}{*}{ RoundsB } & $0.166^{* * *}$ & 0.011 \\
\hline & $(0.053)$ & $(0.078)$ \\
\hline \multirow[t]{2}{*}{ Grim } & -0.214 & 0.001 \\
\hline & $(0.191)$ & $(0.087)$ \\
\hline \multirow[t]{2}{*}{ HLscore } & $-0.144^{*}$ & 0.032 \\
\hline & $(0.086)$ & $(0.027)$ \\
\hline \multirow[t]{2}{*}{$m_{c}$} & & $0.022^{* *}$ \\
\hline & & $(0.009)$ \\
\hline \multirow[t]{2}{*}{$m_{p}$} & & $-0.010^{* *}$ \\
\hline & & $(0.004)$ \\
\hline No. obs. & 1,245 & 350 \\
\hline$R^{2}$ & .520 & .132 \\
\hline
\end{tabular}

Table 22: Random Effects, GLS Regression Analysis of Accepted Proposals in the Modified Design 
amount, 0.166), in the number of rounds of bargaining, and that over all sessions, a higher Holt-Laury score (indicating greater risk aversion) is marginally significant in reducing the quantity agreed upon for exchange purposes. Note finally that the absence of a centralized meeting opportunity has a small negative impact on the quantity traded as indicated by negative and significant coefficient on the NMNC dummy variable. As for the modified money treatment sessions alone (the second column of Table 22) we observe that the number of rounds of bargaining does not seem to matter for the terms of trade $d / q$, which are increasing in the period number and in the amount of money that the consumer has on hand and decreasing slightly with the amount of money the producer has on hand. No other variables are significant in explaining accepted terms of trade. We summarize the main findings as follows:

Finding 11 In the modified design, quantities exchanged are higher with money than without money. Quantities exchanged are also increasing with the number of rounds of bargaining. Finally, the absence of a centralized meeting opportunity results in a small decrease in the quantity exchanged relative to the baseline, no money treatment with a centralized meeting opportunity.

We next focus on behavior in the centralized meeting stage of our modified experimental design. Table 23 reports participation rates, centralized meeting prices and trade volume for both the modified money and no money sessions that made common use of the same trading post mechanism to determine the price of the homogeneous good.

\begin{tabular}{|l|c|c|c|c|c|c|c|}
\hline Session No., & Particp. & \multicolumn{2}{|c|}{ Avg. Centralized Mtg. Price } & \multicolumn{3}{c|}{ Avg. Centralized Mtg. Volume } \\
\cline { 3 - 8 } Treatment & Rate & $1^{\text {st }}$ half & $2^{\text {nd }}$ half & All Periods & $1^{\text {st }}$ half & $2^{\text {nd }}$ half & All Periods \\
\hline \hline 18, MM14 & 0.90 & 1.83 & 1.58 & 1.70 & 27.70 & 25.07 & 26.32 \\
\hline 19, MM14 & 0.79 & 1.63 & 2.48 & 2.08 & 32.39 & 18.25 & 24.98 \\
\hline 20, MM14 & 0.83 & 2.46 & 2.82 & 2.64 & 20.21 & 12.33 & 16.27 \\
\hline 21, MM14 & 0.97 & 2.18 & 1.73 & 1.95 & 25.18 & 21.77 & 23.48 \\
\hline Avg. 18-21 & 0.87 & 2.03 & 2.16 & 2.10 & 26.34 & 19.33 & 22.75 \\
\hline \hline 22, MNM14 & 0.83 & 0.97 & 0.99 & 0.98 & 71.47 & 95.68 & 84.10 \\
\hline 23, MNM14 & 0.69 & 0.98 & 0.97 & 0.98 & 80.18 & 88.56 & 84.37 \\
\hline 24, MNM14 & 0.72 & 0.99 & 1.00 & 0.99 & 116.16 & 132.83 & 124.50 \\
\hline 25, MNM14 & 0.86 & 0.98 & 0.99 & 0.99 & 135.49 & 180.92 & 158.20 \\
\hline Avg. 22-25 & 0.77 & 0.98 & 0.99 & 0.98 & 100.02 & 122.56 & 111.42 \\
\hline \hline
\end{tabular}

Table 23: Participation Rates, Prices and Volume in the Centralized Trading Post of the Money and No Money Sessions of the Modified Design.

We observe that decentralized social norm equilibria, where the centralized meeting is completely avoided, are not selected; participation rates in the centralized trading post meeting were high, averaging 87 percent in the modified money (MM14) sessions and 77 percent in the modified no-money (MNM14) sessions. Using the session level averages reported in 
Table 23 a Mann-Whitney test reveals no difference in these participation rates between the MM14 and MNM14 treatments ( $p=.19$, two-sided test). ${ }^{5}$

Similarly high participation rates in the centralized meeting, averaging 73 percent, were found for the M14 (money) sessions of the Lagos Wright treatment of our experiment. Indeed, rates of participation in the centralized meeting are indistinguishable between the M14 and MM14 sessions $(p=.25$, two-sided Mann-Whitney test using session-level data from Table 8 in the paper and Table 23). What is different is the high participation rate in the centralized meeting by subjects in the no money treatment of the modified experimental design. When the centralized meeting involved the public good mechanism, as in the ACP, no money treatment of our experiment, nearly all subjects learned to contribute zero toward the public good. However, in the modified no money treatment where the centralized meeting involves a trading post mechanism, production and bids for the centralized good are considerably higher. We attribute this finding to differences in the two centralized mechanisms. Under the trading post mechanism of our modified design, if subjects placed bids for good X that were equal to their production of good $\mathrm{X}$, they could always avoid getting a negative payoff (and indeed this is what many subjects chose to do). By contrast, under the binary choice public good centralized mechanism used in the ACP no money treatment of our experiment, agents could earn a negative payoff if they chose to contribute and one or more of the other agents did not. We note that despite these differences, there is no appreciable impact on decentralized trading behavior or on overall welfare.

While the trading post mechanism was held constant, the price and trade volume predictions depend on whether there was money or not. Recall that the monetary equilibrium prediction (in the money treatment) is for a price of 2 and for a trade volume of $4 N$, or 28 when $2 N=14$; the latter prediction is the same for the original design involving the Walrasian call market mechanism. The social norm equilibrium prediction for the no-money treatment in the case where the centralized meeting is used as a signaling device calls for a price of 1 and allows for any contribution between $c(q) * 2 N$ (where $c(q)$ is approximately 1 in the experimental data) and less than or equal roughly to $x * 2 N$ where $x$ should satisfy $\frac{\frac{44 x+12 x^{2}}{12 x+22}}{\frac{1}{2}[7 \ln (1+q)-q]+\frac{44 x+12 x^{2}}{12 x+22}}=\beta \leq \frac{5}{6} .{ }^{6}$ For the MM14 treatment, we find that the mean meeting price of 2.10 is slightly greater than 2 , while the mean trade volume of 22.75 units is somewhat less than 28; nevertheless both means are surprisingly close to the monetary equilibrium prediction. For the MNM14 treatment, we find that the mean meeting price of .99 is only slightly less than 1 and trade volume is close to equilibrium predictions. The small departures, especially in prices, might be attributed to less than full participation by all 14 subjects in the centralized meeting which may also account for the lower than equilibrium quantities being bought and sold in the money (MM14) treatment.

In the money (M14) treatment of the original design involving a Walrasian call market, the price in the centralized meeting was also around 2, as reported in Table 8 of the paper. Indeed, a Mann-Whitney test on the session-level centralized meeting price observations (over

\footnotetext{
${ }^{5} \mathrm{As}$ in the analysis of the money and no money treatments in the paper, participation here refers to the submission of an offer to sell and/or a bid to buy units of the homogeneous good.

${ }^{6}$ For instance, for $q=1.12$ then $\underline{\beta}=\frac{\frac{44 x+12 x^{2}}{12 x+22}}{\frac{1}{2}(7 \ln (2.12)-1.12)+\frac{44 x+12 x^{2}}{12 x+22}} \leq \frac{5}{6}$ for $x \leq 8.83$. See Appendix A for details.
} 
all rounds) reveals no difference in prices as determined by the Walrasian mechanism of the original money treatment (M14) design or by the trading post mechanism of the modified money treatment (MM14) design ( $p=.56$, two-sided test). Thus there is some evidence that the centralized meeting mechanism is not so important to price determination in the centralized meeting stage. On the other hand we do find that trade volume is significantly greater and closer to the equilibrium prediction of 28 in the modified money treatment design as compared with the original money treatment design, $(p=.02$, two-sided test.) Summarizing, we have

Finding 12 In the modified experimental design, there is active participation in the centralized meeting trading post mechanism regardless of whether or not there exists any money. Meeting prices and trade volume are close to or consistent with equilibrium predictions.

We note further that the active participation and positive trade volume in the centralized meeting of the modified no money experimental treatment (MNM14 sessions 22-25) stands in sharp contrast to the near unanimous decision to contribute zero units toward the public good $\mathrm{X}$ in the centralized meeting of the no money treatment (NM14) of our first experiment. Nevertheless, the use of the centralized meeting as a mechanism to signal cooperative behavior does not seem to have resulted in a large quantity of exchange in the decentralized meeting of our modified experimental design.

Finally, we consider again whether subjects in our modified money treatment (MM14 sessions) were using the centralized meeting to re-balance their money holdings. Consistent with finding 7 in the paper we have:

Finding 13 In the modified money treatment with $2 N=14$, the distribution of money holdings at the end of the centralized meeting round is not degenerate. However, we again find evidence that subjects are using the centralized meeting to re-balance their money holdings.

Support for Finding 13 is found in Figures 4-5 and in Table 24. Figure 4 (like Figure 1 of the paper) shows the distribution of token (money) holdings following the completion of the centralized meeting. Here again we first averaged each subjects' token holdings as of the end of each centralized meeting round over the first and over the second halves of each modified money treatment session. These averages were then rounded up to the nearest token. Figure 4a presents a histogram of these average token holdings while Figure 4b shows the cumulative distribution function $(\mathrm{CDF})$ of these token holdings. Consistent with our findings in the first experiment, Figure 4 reveals that the distribution of money holdings following the centralized meeting is not degenerate at 8 tokens. Using the data illustrated in Figure 4, a two-sided Kolmogorov-Smirnov test indicates that the CDF of money holdings for either the first or second halves of the sessions are both significantly different from the CDF associated with a degenerate distribution of money holdings at 8 tokens $(p<.01$ for both one-sample tests). Nevertheless, mean money holdings are centered around 8 tokens in both the first and second halves of the money sessions.

Further, we again find that subjects used the centralized trading post to re-balance their money holdings (token positions). Figure 5, (which parallels the construction of Figures 2-3 in the paper) and Table 24 (which parallels Table 9 of the paper) provide evidence for 


\begin{tabular}{ccccc}
\hline & \multicolumn{4}{c}{ Dependent variable: $\Delta_{C M} m$} \\
Treatment, & MM14 & MM14 & MM14 & MM14 \\
Sess. No. & 1 & 2 & 3 & 4 \\
\hline Cons & 0.000 & 0.000 & 0.000 & 0.013 \\
& $(0.216)$ & $(0.281)$ & $(0.212)$ & $(0.202)$ \\
$\Delta_{D M} m$ & $-0.294^{* * *}$ & $-0.443^{* * *}$ & $-0.727^{* * *}$ & $-0.759^{* * *}$ \\
& $(0.090)$ & $(0.055)$ & $(0.058)$ & $(0.070)$ \\
$\mathrm{R}^{2}$ & 0.040 & 0.178 & 0.359 & 0.298 \\
\hline
\end{tabular}

*** indicates significance at the $1 \%$ significance level.

Table 24: Regression Evidence of Re-balancing in the Centralized Meeting: Coefficient Estimates and (Standard Errors) from a Regression of $\Delta_{C M} m$ on a Constant and $\Delta_{D M} m$ for each Modified Money Treatment (MM14) Session

this re-balancing. Figure 5 shows for each of the four modified money (MM14) treatment sessions a plot of the change of each individual subjects' money holdings at the end of each decentralized meeting round, $\Delta_{D M} m$, against the change in the same individual's money holdings at the end of the subsequent centralized meeting round, denoted by $\Delta_{C M} m$. Table 24 reports a regression analysis of $\Delta_{D M} m$ and $\Delta_{C M} m$, of the same type reported for the first experiment in Table 9 of the paper. Figure 5 and Table 24 again indicate a strong negative relationship between $\Delta_{D M} m$ and $\Delta_{C M} m$, which is consistent with the use of the centralized meeting for token re-balancing. The fitted (red solid) line shown Figure 5 for each session has a slope coefficient that is negative and significantly different from zero $(p<.01$ for all 4 sessions) as indicated in Table $24 .{ }^{7}$ While the equilibrium prediction would call for perfect re-balancing, (i.e., $\Delta_{D M} m=-\Delta_{C M} m$ ) as indicated by the dashed 45 degree line in Figure 5, the experimental data again suggest that re-balancing was less than perfect in that $\left|\Delta_{D M} m\right|>\left|\Delta_{C M} m\right|$. More precisely, the regression coefficients on $\Delta_{D M} m$ as reported in Table 24 are always significantly less than 1 according to Wald tests $(p<.01$ for all 4 sessions). As in our first experiment this is indicative of possible precautionary hoarding of money balances relative to monetary equilibrium predictions, but it may also simply reflect out-of-equilibrium behavior in both the decentralized and centralized meetings.

Summarizing, we have provided evidence in this appendix that many of the findings found using our original experimental design are also found in the data collected using our modified experimental design involving up to three rounds of bargaining and the same trading post mechanism in the centralized meeting stage of both the money and no money treatments.

\section{Appendix C: Experimental Instructions}

The following pages contain copies of the instructions used in both parts of the experiment reported on in the paper "Gift Exchange versus Monetary Exchange: Theory and Evidence" by John Duffy and Daniela Puzzello. Specifically, instructions used in the M14, NM14, MM14, MNM14, and MNMNC14 treatments of that experiment (in that order) are included. The instructions for the M6 and NM6 treatments are similar to the M14 and NM14 treatment

\footnotetext{
${ }^{7}$ The results reported are from a random effects, GLS regression on data for each money treatment session.
} 
with the only change being to the number of subjects (6 rather than 14$)$.

Also included in this section are the instructions used to conduct the Holt-Laury (2002) paired lottery choice experiment that was used to elicit individual subjects' risk attitudes and which was administered following the completion of the main, M or NM treatments. 


\section{Instructions}

Welcome to this experiment in the economics of decision making. Funding for this experiment has been provided by the University of Pittsburgh. During today's session, you will be called upon to make a series of decisions. If you follow the instructions carefully and make good decisions, you can earn a considerable amount of money that will be paid to you in cash at the end of the experiment. Please, no talking for the duration of today's session.

We will first go over the instructions. When we are done, each of you will have to answer a few brief questions to ensure that everyone understands these instructions. You will also have time to ask clarifying questions. Then, you will begin making your decisions using the computer workstations.

\section{Overview}

There are 14 people participating in today's session. Each participant will make consuming, producing, buying or selling decisions in a number of sequences. Each sequence consists of an unknown number of periods. Each period consists of two rounds. At the end of each two-round period, the computer program will draw a random number, specifically, an integer in the set $\{1,2,3,4,5,6\}$. Each of these six numbers has an equal chance of being chosen; it is like rolling a six-sided die. The program will display the random number chosen on all participants' screens. If the random number is $1,2,3,4$ or 5 , the sequence will continue with another two-round period. If the random number is a 6 , the sequence will end. Thus the probability a sequence continues from one period to the next is $5 / 6$ and the probability it ends after each period is $1 / 6$. If a sequence ends, then depending on the time available, a new sequence will begin.

You will start today's experiment with an endowment of 20 points. Over the course of a sequence you may gain or lose points based on the decisions you make as will be explained in detail below. Your point total will carry over from one sequence to the next. Your final point total from all sequences played will determine your earnings for the experiment. Each point you earn is worth $\$ 0.20$.

At the beginning of each sequence, each of the 14 participants is endowed with 8 "tokens". The total number of tokens, $(14 \times 8=112)$ is fixed for the duration of each sequence. Participants may choose whether or not to use tokens for exchange purposes as discussed below. Tokens have no value in terms of points.

\section{Timing and Pairing}

Recall that each period consists of two rounds. In the first round of each new period, the 14 participants will be randomly matched in 7 pairs and make decisions with one another in a Decentralized Market. In the second and final round of each period, all 14 participants will interact together in a Centralized Market. We will now desribe what happens in each of these two rounds of a period. 


\section{Round 1: Decentralized Market}

At the beginning of each Decentralized Market-the first round of each period-each participant is randomly paired with one other participant. All pairings are equally likely. In each pair, one participant is randomly chosen to be the Consumer and the other is the Producer. At the start of each Decentralized Market round, you are equally likely to be assigned either role; it is as though a coin flip determines whether you are a Producer or Consumer in each round. Both participants will be informed about the token holdings of the other participant in their pair. In the Decentralized Market, a perishable good is produced and can be traded. This good cannot be carried over into any other round or period. Producers incur a cost in points for producing some quantity of the perishable good which is subtracted from their point total and Consumers receive a benefit in points from consuming some quantity of the perishable good which is added to their point total. Table 1 summarizes how costs and benefits are related to your point earnings. For example, if you are a Producer and agree to produce 2 units of the good, you incur a production cost of 2 points. If you are a Consumer and you succeed in consuming 7 units of the good, you get a benefit of 14.56 points.

\begin{tabular}{|c|c|c|}
\hline Quantity & Producer's Cost (Points) & Consumer's Benefit (Points) \\
\hline \hline 0 & 0 & 0.00 \\
\hline 1 & -1 & 4.85 \\
\hline 2 & -2 & 7.69 \\
\hline 3 & -3 & 9.70 \\
\hline 4 & -4 & 11.27 \\
\hline 5 & -5 & 12.54 \\
\hline 6 & -6 & 13.62 \\
\hline 7 & -7 & 14.56 \\
\hline 8 & -8 & 15.38 \\
\hline 9 & -9 & 16.12 \\
\hline 10 & -10 & 16.78 \\
\hline 11 & -11 & 17.39 \\
\hline 12 & -12 & 17.95 \\
\hline 13 & -13 & 18.47 \\
\hline 14 & -14 & 18.96 \\
\hline 15 & -15 & 19.40 \\
\hline 16 & -16 & 19.83 \\
\hline 17 & -17 & 20.23 \\
\hline 18 & -18 & 20.61 \\
\hline 19 & -19 & 20.97 \\
\hline 20 & -20 & 21.31 \\
\hline 21 & -21 & 21.64 \\
\hline 22 & -22 & 21.95 \\
\hline
\end{tabular}

Table 1: Cost and Benefit (in Points) for Producers and Consumers, Decentralized Market 
You have been matched with another participant. In this meeting you are the consumer and the other participant is the producer.

Your token holdings:

The other player's token holdings:

Please enter a quantity between 0 and 22 of the good you want from the producer with whom you are matched this round

Please enter the number, between 0 and of your token holdings you are willing to offer for the quantity you entered in the box above.

Figure 1: Consumer's Decision Screen, Decentralized Market

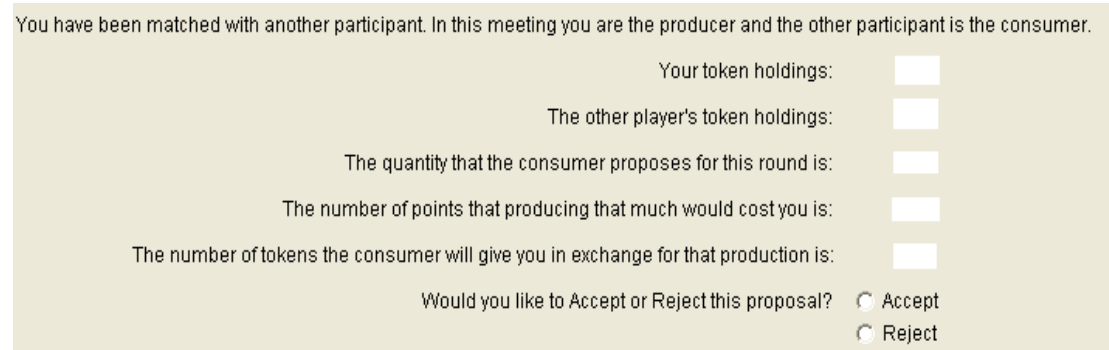

Figure 2: Producer's Decision Screen, Decentralized Market 
Consumers move first. They are informed of their own token holdings as well as the token holdings of their Producer and then they must decide how many units of the perishable good they want the Producer to produce for them and how many tokens they are willing to give the Producer for this amount of goods - see Figure 1. Consumers can request any amount of the good between 0 and 22 units inclusive (fractions allowed) and they can offer to give the Producer between 0 and the maximum number of tokens they currently have available, inclusive (fractions allowed). After all Consumers have made their decisions, Producers are informed of their own token holdings as well as the token holdings of their Consumer. They are then presented with their matched Consumer's proposal (amount of good / tokens offered in exchange). Producers must decide whether to accept or reject the proposal of their matched Consumer - see Figure 2. If they choose 'Accept', the trade takes place: Producers produce the requested amount of the good, incur costs in points for doing so but receive the amount of tokens, if any, the Consumer offered in exchange. Consumers will receive the benefit from their consumption of the amount of the good produced in points but lose any tokens they have offered to the Producer as part of the exchange. If the Producer choose 'Reject', then no trade takes place: the token and point balances of both participants will remain unchanged. Once the results of the decentralized market (round 1) are revealed and any trades are implemented, we move on to the Centralized Market-round 2.

\section{Round 2: Centralized Market}

In the second round of a period, all participants have the opportunity to interact in a single Centralized market (there is no pairwise matching in the Centralized Market). Each participant brings with him/her the token holdings s/he had at the end of round 1 (the Decentralized Market) after any trades have taken place in that round. In the Centralized Market, each participant can decide whether to produce-and-sell or buy-and-consume units of a perishable good called "good X". Participants can also decide to abstain from participating in the Centralized Market for good X. The decision screen you face in the Centralized Market is shown in Figure 3.

Table 2 shows the points you can earn from buying and selling units of Good X. For instance, if you decide to sell 2 units of good $\mathrm{X}$ and you are able to sell those units (more on this below), then producing those two units will cost you 2 points. If you decide to buy 7 units of good $\mathrm{X}$ and you are able to buy those units (again, see below), this will give you a benefit of 7 points. 
Please indicate whether you would like to either:

C Produce and sell units of good $X$ in the centralized market in exchange for more tokens

$C$ Buy units of good $X$ in the centralized market using my current token holdings

$\checkmark$ Do not wish to participate in the centralized market this round

Figure 3: Decision Screen, Centralized Market

\begin{tabular}{|c|c|c|}
\hline Quantity & Produce-and-Sell Cost (Points) & Buy-and-Consume Benefit (Points) \\
\hline 0 & 0 & 0 \\
\hline 1 & -1 & 1 \\
\hline 2 & -2 & 2 \\
\hline 3 & -3 & 3 \\
\hline 4 & -4 & 4 \\
\hline 5 & -5 & 5 \\
\hline 6 & -6 & 6 \\
\hline 7 & -7 & 7 \\
\hline 8 & -8 & 8 \\
\hline 9 & -9 & 9 \\
\hline 10 & -10 & 10 \\
\hline 11 & -11 & 11 \\
\hline 12 & -12 & 12 \\
\hline 13 & -13 & 13 \\
\hline 14 & -14 & 14 \\
\hline 15 & -15 & 15 \\
\hline 16 & -16 & 16 \\
\hline 17 & -17 & 17 \\
\hline 18 & -18 & 18 \\
\hline 19 & -19 & 19 \\
\hline 20 & -20 & 20 \\
\hline 21 & -21 & 21 \\
\hline 22 & -22 & 22 \\
\hline
\end{tabular}

Table 2: Cost and Benefit (in Points) for Producers and Consumers, Centralized Market

After all have decided whether to 1) produce and sell good X, 2) buy (and consume) good $\mathrm{X}$ or 3) not participate in the Centralized Market for good X, participants who have decided to produce and sell units of good $\mathrm{X}$ must state how many units they would like to offer for sale and participants who have decided to buy units of good X must state how many units 
they would like to buy. Following that decision, "sellers" must state the minimum number of tokens (price) they are willing to accept for each unit they offer for sale and "buyers" must state the maximum number of tokens (price) they are willing to pay for each unit they want to buy. As a buyer (seller) you can buy (sell) any number of units of good X from 0 to 22 inclusive (fractions are allowed). You can enter only one buy (sell) price (per unit) for all of the units you want to buy (sell). Note that for a buyer, the number of units of good X desired times the price per unit offered cannot exceed the buyer's current total token holdings; the program will inform buyers of the maximum price per unit of good $\mathrm{X}$ they can offer given the quantity of good $\mathrm{X}$ they wish to purchase and their current available token holdings.

After any/all quantities and prices have been submitted, the computer program ranks all buy offers from highest to lowest forming a market demand schedule and all sell offers from lowest to highest forming a market supply schedule. The program then finds the intersection of market demand and market supply. That intersection gives the market price. If there is no intersection because either all sell prices lie above all buy prices, or there is no participant on one or both sides of the centralized market (no buyers and/or no sellers), then there is no market price and no exchange of good $\mathrm{X}$ for tokens in the centralized market; in the latter case, your screen indicates "No Market Price" and your point total and token holdings are unchanged. Note that for there to be a market price and exchange in the centralized market, there must be both buyers and sellers of good X.

Suppose there is a market price. In that case, every transaction occurs at this market price. Those whose buy offers were greater than the market price get to buy units of good X at the market price using their tokens and those whose sell offers are below the market price get to sell units of good $\mathrm{X}$ at the market price in exchange for tokens. While you may have requested to sell 2 units or buy 7 , you may not be able to make such trades if your sell price is too high or your buy price is too low. In such cases, you do not sell or buy any units of good $X$ and your token and point holdings are unchanged. Those participants whose buy or sell offers are equal to the market price might also get rationed, depending on whether there are more units for sale than there are buyers or the other way around. If there are more units for sale than there are buyers, not all sellers will be able to sell. If there are more units demanded than are for sale, not all buyers will be able to buy. In those cases the computer randomly determines who gets to sell or to buy. All participants are informed about the market price. Again, if you are unable to buy or sell your point and token holdings remain unchanged.

Notice that successful buyers in the centralized market will leave that market with reduced token balances but higher point totals while successful sellers in the centralized market will leave that market with increased token balances but lower point totals. These new token balances will carry over to the decentralized market of the next period of the sequence, if there is a next period. 


\section{Information}

After each round, all participants will be informed about their point totals and their token holdings. After round 1 (Decentralized Market) participants will also be informed about the point totals and the token holdings of the participant they have been matched with. Nobody will ever be informed about the identity of the participant they are paired with. After round 2 (Centralized Market) you will see your token and point totals both for the Decentralized Market round, the Centralized Market Round, the period (rounds 1 and 2 combined) and your cumulative point total for the current sequence. For your convenience, beginning with round 2 of a sequence, you will see the history of your decisions in prior rounds of the decentralized market (DM) or the centralized market (CM).

\section{Determination of your Earnings}

At the end of today's session, your point total from all sequences played, including the initial 20 points you were given at the start of the experiment will be converted into dollars at the rate of 1 point $=\$ 0.20$.

\section{Summary}

1. You start with 20 points. You will play an unknown number of sequences. Your point total accumulates over all sequences.

2. Each sequence consists of a number of periods. At the beginning of each sequence, all participants are endowed with 8 tokens. Tokens have no value in terms of points.

3. Each period in a sequence consists of two rounds.

\section{Round 1 Decentralized Market:}

i. Participants are randomly matched in pairs with one member of the pair randomly chosen to be the Consumer and the other chosen to be the Producer. Both roles are equally likely.

ii. Consumers decide how many units of a perishable good to request from the Producer they are matched with and how many tokens to offer the Producer for those units.

iii. Producers decide whether to accept or reject their matched Consumer's proposal.

iv. If accepted, the Consumer's point earnings are increased as in Table 1. The Consumer's token holdings are decreased by the amount offered to the Producer. The Producer's point earnings are decreased by the cost of producing the amount of the good. The Producer's token holdings are increased by the amount she receives from the Consumer in exchange for producing the good. 
v. Participants are informed about the point earnings and token holdings in their pair.

\section{Round 2 Centralized Market:}

i. All participants interact together in the Centralized Market to decide whether to buy sell or not participate in the market for a perishable good $X$.

ii. Participants who decide to buy state the quantity of units they wish to buy and the maximum number of tokens they are willing to pay for each unit they wish to buy. Participants who decide to sell state the quantity of units they wish to sell and the minimum number of tokens they are willing to accept for each unit they wish to sell.

iii. A central market clearing mechanism sorts all buy offers from highest to lowest and all sell offers from lowest to highest. A single market price is determined that clears the market, i.e., the price that ensures that as many units are bought as are sold.

iv. A buyer's point earnings are increased by the number of units of good $X$ bought and her token holdings are decreased by the market price times the number of units she is able to buy. A seller's point earnings are reduced by the number of units of good $X$ sold and his token holdings are increased by the market price times the number of units sold. Those not participating in the centralized market or those who were unable to buy or sell in the centralized market will not see any changes in their point totals or token holdings.

v. Participants are informed of the market price and about their own point earnings and token holdings.

4. At the end of each period, a number (integer) from 1-6 is randomly drawn and determines whether the sequence continues with another 2 -round period. If a $1,2,3,4$ or 5 is drawn the sequence continues. If a 6 is drawn, the sequence ends. Thus, there is a $5 / 6$ chance that a sequence continues and a $1 / 6$ chance that it ends.

5. If a sequence continues, a new period begins. Token balances carry over from the prior period and participants are randomly paired anew in the Decentralized Market (round 1). If a sequence ends, token balances are set to zero. Depending on the time available, a new sequence will begin. Each participant starts a new sequence with 8 tokens.

6. Points accumulate over all sequences. At the end of the session, each participant's cumulative point total will be converted into cash at the rate of 1 point $=\$ 0.20$. Token holdings can be carried over from round to round and period to period, but not from sequence to sequence.

\section{Questions?}

Now is the time for questions about these instructions. If you have a question, please raise your hand and an experimenter will come to you. 


\section{Quiz}

Before we start, we would like you to answer a few questions that are meant to review the rules of today's experiment. The numbers that appear in these questions are for illustration purposes only; the actual numbers in the experiment may be different. When you are done answering these questions, raise your hand and an experimenter will check your answers.

1. How many rounds are there in each period?

2. Suppose it is period 2 of a sequence. What is the probability that the sequence continues with a period 3? Would your answer be any different if we replaced period 2 with period 12 and period 3 with period 13 ? Circle one: yes/no.

3. Can you choose whether you are a producer or consumer in the first round of a period, i.e. the decentralized market?

4. Can you choose whether you are a buyer or seller in the second round of a period, i.e. the centralized market?

5. Can you carry over token holdings from period to period? From sequence to sequence?

6. Can you choose different prices for units bought/sold in the centralized market?

7. Suppose you start round 1 (Decentralized Market) holding 4 tokens. Suppose further that you are the Consumer. You propose to buy and consume 2 units in exchange for all 4 of your tokens and the Producer accepts your proposal.

a. What are your additional point earnings this round? (Use Table 1)

b. What are your token holdings at the beginning of round 2? (Centralized Market)

8. Suppose you enter round 2 with 0 tokens. Suppose you choose to be a seller, you offer 2 units at a price lower than 1 . The market price turns out to be 1 so you are able to sell your 2 units

a. What are your additional point earnings this round? (Use Table 2)

b. What are your token holdings at the beginning of the next period if the random draw is a 3 ? If the random draw is a 6 , do your token holdings carry over to the next period? Circle one: yes / no

c. If the sequence continues and you are a Consumer in the round 1 of the next period, what is the maximum number of tokens you can offer the Producer you are matched with in exchange for the good in the Decentralized Market? 
9. Suppose you enter round 2 with 0 tokens. You again choose to be a seller, and you offer 2 units at a price higher than 2. The market price turns out to be 2 .

a. What are your additional point earnings this round? (Use Table 2)

b. What are your token holdings?

c. If the sequence continues and you are a Consumer in round 1 of the next period, what is the maximum number of tokens you can offer the Producer you are matched with in exchange for the good in the Decentralized Market?

10. True or False: Your point total from all sequences will be converted into money and paid to you in cash at the end of the session. Circle one: True False. 


\section{Instructions}

Welcome to this experiment in the economics of decision making. Funding for this experiment has been provided by the University of Pittsburgh. During today's session, you will be called upon to make a series of decisions. If you follow the instructions carefully and make good decisions, you can earn a considerable amount of money that will be paid to you in cash at the end of the experiment. Please, no talking for the duration of today's session.

We will first go over the instructions. When we are done, each of you will have to answer a few brief questions to ensure that everyone understands these instructions. You will also have time to ask clarifying questions. Then, you will begin making your decisions using the computer workstations.

\section{Overview}

There are 14 people participating in today's session. Each participant will make consuming and producing decisions in a number of sequences. Each sequence consists of an unknown number of periods. Each period consists of two rounds. At the end of each two-round period, the computer program will draw a random number, specifically, an integer in the set $\{1,2,3,4,5,6\}$. Each of these six numbers has an equal chance of being chosen; it is like rolling a six-sided die. The program will display the random number chosen on all participants' screens. If the random number is $1,2,3,4$ or 5 , the sequence will continue with another tworound period. If the random number is a 6 , the sequence will end. Thus the probability a sequence continues from one period to the next is $5 / 6$ and the probability it ends after each period is $1 / 6$. If a sequence ends, then, depending on the time available, a new sequence will begin.

You will start today's experiment with an endowment of 20 points. Over the course of a sequence you may gain or lose points based on the decisions you make as will be explained in detail below. Your point total will carry over from one sequence to the next. Your final point total from all sequences played will determine your earnings for the experiment. Each point you earn is worth $\$ 0.20$.

\section{Timing and Pairing}

Recall that each period consists of two rounds. In the first round of each period, the 14 participants will be randomly matched in 7 pairs and make decisions with one another in a Decentralized Meeting. In the second and final round of each period, all 14 participants will interact together in a Centralized Meeting. We will now describe what happens in each of these two rounds of a period.

\section{Round 1: Decentralized Meeting}

At the beginning of each Decentralized Meeting-the first round of each period-each participant is randomly paired with one other participant. All pairings are equally likely. In each 
pair, one participant is randomly chosen to be the Consumer and the other is the Producer. At the start of each Decentralized Meeting round, you are equally likely to be assigned either role; it is as though a coin flip determines whether you are a Producer or Consumer in each round. In the Decentralized Meeting, a perishable good is produced and can be traded. This good cannot be carried over into any other round or period. Producers incur a cost in points for producing some quantity of the perishable good which is subtracted from their point total and Consumers receive a benefit in points from consuming some quantity of the perishable good which is added to their point total. Table 1 summarizes how costs and benefits are related to your point earnings. For example, if you are a Producer and agree to produce 2 units of the good, you incur a production cost of 2 points. If you are a consumer and you succeed in consuming 7 units of the good, you get a benefit of 14.56 points.

\begin{tabular}{|c|c|c|}
\hline Quantity & Producer's Cost (Points) & Consumer's Benefit (Points) \\
\hline 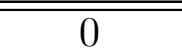 & $\begin{array}{l}0 \\
\end{array}$ & 0.00 \\
\hline 1 & -1 & 4.85 \\
\hline 2 & -2 & 7.69 \\
\hline 3 & -3 & 9.70 \\
\hline 4 & -4 & 11.27 \\
\hline 5 & -5 & 12.54 \\
\hline 6 & -6 & 13.62 \\
\hline 7 & -7 & 14.56 \\
\hline 8 & -8 & 15.38 \\
\hline 9 & -9 & 16.12 \\
\hline 10 & -10 & 16.78 \\
\hline 11 & -11 & 17.39 \\
\hline 12 & -12 & 17.95 \\
\hline 13 & -13 & 18.47 \\
\hline 14 & -14 & 18.96 \\
\hline 15 & -15 & 19.40 \\
\hline 16 & -16 & 19.83 \\
\hline 17 & -17 & 20.23 \\
\hline 18 & -18 & 20.61 \\
\hline 19 & -19 & 20.97 \\
\hline 20 & -20 & 21.31 \\
\hline 21 & -21 & 21.64 \\
\hline 22 & -22 & 21.95 \\
\hline
\end{tabular}

Table 1: Cost and Benefit (in Points) for Producers and Consumers, Decentralized Meeting

Consumers move first and decide how many units of the perishable good they want from the Producer (see Figure 1). 
Consumers can request any amount of the good between 0 and 22 inclusive (fractions allowed). After all Consumers have made their decisions, Producers are informed of their matched Consumer's proposal. Producers decide whether to accept or reject the proposal of their matched Consumer (see Figure 2). If they accept, the trade takes place: Producers will produce the requested amount of the good and incur a cost in points for doing so. Consumers will receive the benefit from their consumption of the amount of the good produced in points. If the Producer rejects, no trade takes place: the point balances of both participants will remain unchanged. Once the results of the Decentralized Meeting (round 1) are revealed and any trades are implemented, we move on to the Centralized Meeting (round 2). Press the continue button when you are ready to move on.

\section{Round 2: Centralized Meeting}

In the second round of a period, all 14 participants have the opportunity to interact with one another in a single meeting (there is no pairwise matching in the Centralized Meeting). Each participant must independently and anonymously decide whether to produce 0 or 1 units of a perishable good called good $X$. After production decisions have been made, all participants will receive the average number of units of good $X$ that were produced. The cost of producing 1 unit of good $X$ is 1 point. The consumption benefit from 1 unit of good $X$ is also 1 point. The decision screen for the Centralized Meeting round is shown in Figure 


\section{Decentralized Meeting}

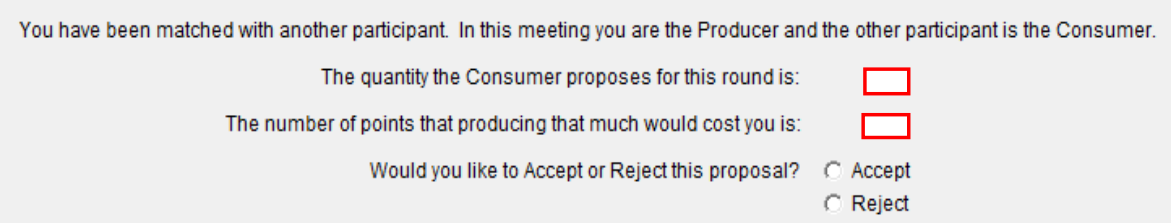

Figure 2: Producer's decision screen in the Decentralized Meeting (round 1)

3.

After all participants have made their production of good $X$ decisions, the program will calculate how many units of good $X$ were produced by all participants. This sum will be divided by the total number of participants (14) to determine the average number of units of good $X$ that were produced, a number between 0 and 1 inclusive. All participants who chose to produce a unit of good $X$ will be charged 1 point. All participants, even those who chose to produce 0 units of good $X$, will be credited with the average number of units of good $X$ produced and the corresponding number of points.

Consider the following examples.

Example 1: Suppose that all participants choose to produce 1 unit of good $X$. The average number of units produced of good $X$ is therefore 1 . In that case, all individuals will pay 1 point for producing their 1 unit of good $X$. They will receive, in exchange, the average number of units of good $X$ that were produced, in this case, 1 , which has a benefit value of 1 point. Thus, each participant's net payoff is 0 points: each pays 1 point to produce 1 unit of good $X$ and each gains 1 point from receiving the average number of units produced of $\operatorname{good} X$.

Example 2: Suppose that one-half of individuals choose to produce 1 unit of good $X$ and the other half choose to produce 0 units of good $X$. The average number of units produced of good $X$ is therefore 0.5 . Those participants who produced 1 unit of good $X$ will pay 1 point and receive back 0.5 units of good $X$, which is worth 0.5 points. Their net payoff is 
Figure 3: Decision screen faced by all participants in the Centralized Meeting (round 2)

therefore -0.5 points. Those participants who produced 0 units of good $X$ will pay 0 points and receive back 0.5 units of good $X$, which is worth 0.5 points. Their net payoff is therefore 0.5 points.

Example 3: Suppose that all participants choose to produce 0 units of good $X$. The average number of units produced of good $X$ is therefore 0 . Thus, each participant's net payoff is 0 points: each pays 0 points by not producing a unit of good $X$ and each gains 0 points from receiving 0 units of good $X$.

More generally, your net payoff in points from the Centralized Meeting is given by the formula:

$$
\text { average production of good } X \text { - your production of good } X \text {. }
$$

Once all participants have entered their decision regarding production of good $X$, the results for the Centralized Meeting will appear on your screen. You will learn the average number of units of good $X$ produced and you will be reminded of how many units of good $X$ you chose to produce. Finally, you will learn your net payoff in points for the Centralized Meeting round. When you have viewed these results, press the continue button indicating that you are ready to move on. 


\section{Information}

After each round, all participants will be informed of their point totals. After round 1 (Decentralized Meeting), you will be informed about both your point earnings and the point earnings of the participant you were paired with. Nobody will ever be informed of the identity of the participant they are paired with. After round 2 (Centralized Meeting), you will see your point earnings from the Centralized Meeting round as well as your point earnings for the period (rounds 1 and 2 combined) and your cumulative point total for the current sequence. For your convenience, beginning with period 2 of a sequence, you will see a history of the decisions you made in earlier Decentralized Meeting (DM) or Centralized Meeting (CM) rounds prior to making your decisions in those rounds.

\section{Determination of your Earnings}

At the end of today's session, your point total from all sequences played, including the initial

20 points you were given at the start of the experiment will be converted into dollars at the rate of 1 point $=\$ 0.20$.

\section{Summary}

1. You start with 20 points. You will play an unknown number of sequences. Your point total accumulates over all sequences.

2. Each sequence consists of a number of periods.

3. Each period in a sequence consists of two rounds.

\section{Round 1 Decentralized Meeting:}

i. Participants are randomly matched in pairs with one member of the pair randomly chosen to be the Consumer and the other chosen to be the Producer. Both roles are equally likely.

ii. Consumers decide how many units of a perishable good to request from the Producer they are matched with.

iii. Producers decide whether to accept or reject their matched Consumer's proposal.

iv. If accepted, the Consumer's point earnings are increased as in Table 1. The Producer's point earnings are decreased by the cost of producing the amount of the good.

v. Participants are informed about the point earnings in their pair.

\section{Round 2 Centralized Meeting:}

i. All participants interact together in the Centralized Meeting to decide on the production of a perishable good $X$. 
ii. Participants choose whether to produce 0 or 1 units of good $X$.

iii. The total number of units of good $X$ produced by all participants is calculated. This total is divided by the total number of participants to determine the average number of units of good $X$ produced.

iv. Producers of 1 unit of good $X$ are charged 1 point. All participants receive the average number of units of good $X$ produced, worth a benefit of 1 point per unit of good $X$ received.

4. At the end of each period, a number (integer) from 1-6 is randomly drawn and determines whether the sequence continues with another 2 -round period. If a $1,2,3,4$ or 5 is drawn the sequence continues. If a 6 is drawn, the sequence ends. Thus, there is a $5 / 6$ chance that a sequence continues and a $1 / 6$ chance that it ends.

5. If the sequence continues, a new period begins. Participants are randomly paired anew in the Decentralized Meeting (round 1). If the sequence ends, then, depending on the time available, a new sequence will begin.

6. Points accumulate over all sequences. At the end of the session, each participant's cumulative point total will be converted into cash at the rate of 1 point $=\$ 0.20$.

\section{Questions?}

Now is the time for questions about these instructions. If you have a question, please raise your hand and an experimenter will come to you.

\section{Quiz}

Before we start, we would like you to answer a few questions that are meant to review the rules of today's experiment. The numbers that appear in these questions are for illustration purposes only; the actual numbers in the experiment may be different. When you are done answering these questions, raise your hand and an experimenter will check your answers.

1. How many rounds are there in each period?

2. Suppose it is period 2 of a sequence. What is the probability that the sequence continues with a period 3 ? Would your answer be any different if we replaced period 2 with period 12 and period 3 with period 13? Circle one: yes / no.

3. Can you choose whether you are the Producer or the Consumer in the first round of a period, i.e., the Decentralized Meeting? Circle one: yes / no.

4. Can you choose how many units of good $X$ that you produce in the Centralized Meeting? Circle one: yes / no. 
5. Suppose in the Decentralized Meeting (round 1) that you are randomly selected to be the Consumer. You propose that the Producer produce 2 units for you to consume. Suppose further that the Producer accepts your proposal.

a. What are your additional point earnings this round? (Use Table 1)

b. What is the Producer's cost in points from producing the amount you requested?

6. Suppose in the Centralized Meeting (round 2) that you decide to produce 1 unit of $\operatorname{good} X$.

a. Suppose the average number of units of good $X$ produced by all participants turns out to be 1 . What is your net payoff in points for the Centralized Meeting (round 2) in this case?

b. Suppose average number of units of good $X$ produced by all participants instead turns out to be 0.5 . What is your net payoff in points for the Centralized Meeting (round 2) in this case?

7. Suppose this period that you were a Consumer in the Decentralized Meeting (round 1). At the end of the period, following the Centralized Meeting (round 2), the random number drawn is a 3 , so that the sequence continues with another period. What is the probability that you will again be the Consumer in the next Decentralized Meeting (new round 1)? What is the probability that you will be the Producer?

8. True or False: Your point total from all sequences will be converted into money and paid to you in cash at the end of the session. Circle one: True False. 


\section{Instructions}

Welcome to this experiment in the economics of decision making. Funding for this experiment has been provided by the University of Pittsburgh. During today's session, you will be called upon to make a series of decisions. If you follow the instructions carefully and make good decisions, you can earn a considerable amount of money that will be paid to you in cash at the end of the experiment. Please, no talking for the duration of today's session.

We will first go over the instructions. When we are done, each of you will have to answer a few brief questions to ensure that everyone understands these instructions. You will also have time to ask clarifying questions. Then, you will begin making your decisions using the computer workstations.

\section{Overview}

There are 14 people participating in today's session. Each participant will make consuming, producing, buying or selling decisions in a number of sequences. Each sequence consists of an unknown number of periods. Each period consists of two rounds. At the end of each two-round period, the computer program will draw a random number, specifically, an integer in the set $\{1,2,3,4,5,6\}$. Each of these six numbers has an equal chance of being chosen; it is like rolling a six-sided die. The program will display the random number chosen on all participants' screens. If the random number is $1,2,3,4$ or 5 , the sequence will continue with another two-round period. If the random number is a 6 , the sequence will end. Thus the probability a sequence continues from one period to the next is $5 / 6$ and the probability it ends after each period is $1 / 6$. If a sequence ends, then depending on the time available, a new sequence will begin.

You will start today's experiment with an endowment of 20 points. Over the course of a sequence you may gain or lose points based on the decisions you make as will be explained in detail below. Your point total will carry over from one sequence to the next. Your final point total from all sequences played will determine your earnings for the experiment. Each point you earn is worth $\$ 0.30$.

At the beginning of each new sequence, each of the 14 participants is endowed with 8 "tokens". The total number of tokens, $(14 \times 8=112)$ is fixed for the duration of each sequence. Participants may choose whether or not to use tokens for exchange purposes as discussed below. Tokens have no value in terms of points.

\section{Timing and Pairing}

Recall that each period consists of two rounds. In the first round of each new period, the 14 participants will be randomly matched in 7 pairs and make decisions with one another in a Decentralized Meeting. In the second and final round of each period, all 14 participants will interact together in a Centralized Meeting. We will now describe what happens in each of these two rounds of a period. 


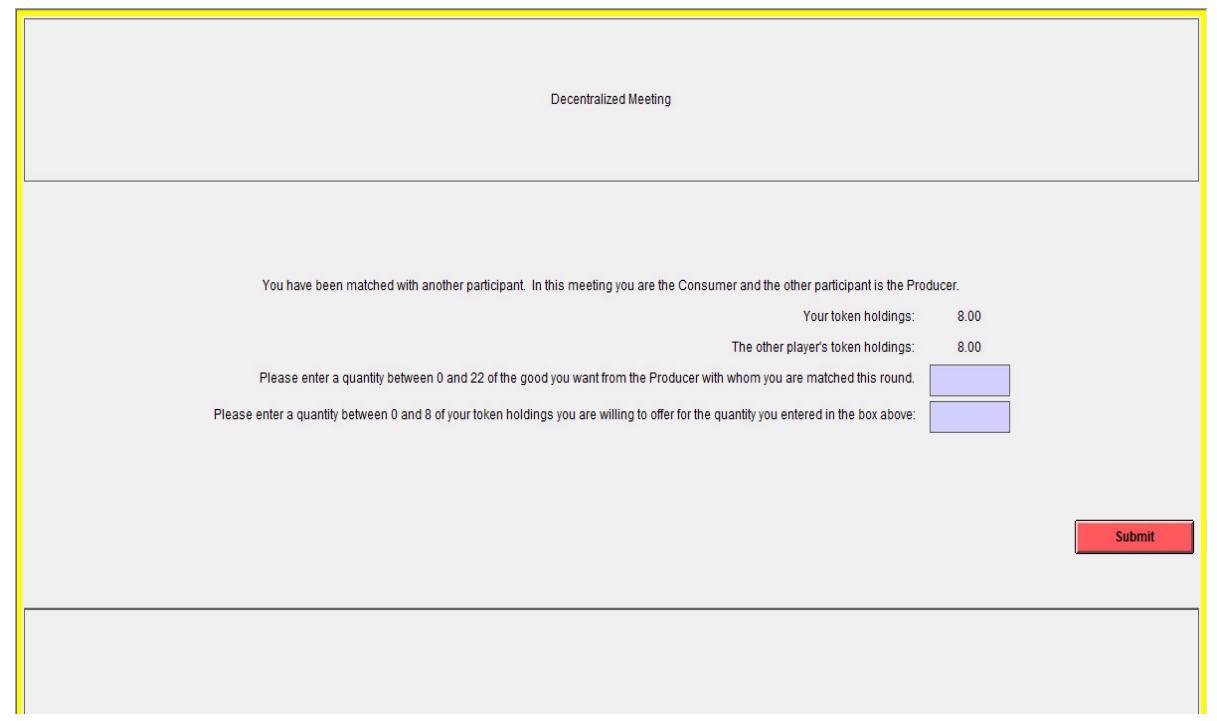

Figure 1: Initial Consumer Decision Screen, Decentralized Meeting.

\section{Round 1: Decentralized Meeting}

At the beginning of each Decentralized Meeting-the first round of each period-each participant is randomly paired with one other participant. All pairings are equally likely. In each pair, one participant is randomly chosen to be the Consumer and the other is the Producer. At the start of each Decentralized Meeting round, you are equally likely to be assigned either role; it is as though a coin flip determines whether you are a Producer or Consumer in each round. Both participants will be informed about the token holdings of the other participant in their pair. In the Decentralized Meeting, a perishable good is produced and can be traded. This good is "perishable" because it cannot be carried over into any other round or period. Producers incur a cost in points for producing some quantity of this perishable good which is subtracted from their point total and Consumers receive a benefit in points from consuming some quantity of the perishable good which is added to their point total. Table 1 summarizes how costs and benefits are related to your point earnings. For example, if you are a Producer and agree to produce 2 units of the good, you incur a production cost of 2 points. If you are a Consumer and you succeed in consuming 7 units of the good, you get a benefit of 14.56 points.

Consumers move first. They are informed of their own token holdings as well as the token holdings of their matched Producer. Then the Consumer must decide how many units of the perishable good they want their matched Producer to produce for them and how many tokens they are willing to give that Producer for this amount of goods -see Figure 1. Consumers can request any amount of the good between 0 and 22 units inclusive (fractions allowed) and they can offer to give the Producer between 0 and the maximum number of tokens they currently have available, inclusive (fractions allowed). After all Consumers have made their 


\begin{tabular}{|c|c|c|}
\hline Quantity & Producer's Cost in Points & Consumer's Benefit in Points \\
\hline \hline 0 & 0 & 0.00 \\
\hline 1 & -1 & 4.85 \\
\hline 2 & -2 & 7.69 \\
\hline 3 & -3 & 9.70 \\
\hline 4 & -4 & 11.27 \\
\hline 5 & -5 & 12.54 \\
\hline 6 & -6 & 13.62 \\
\hline 7 & -7 & 14.56 \\
\hline 8 & -8 & 15.38 \\
\hline 9 & -9 & 16.12 \\
\hline 10 & -10 & 16.78 \\
\hline 11 & -11 & 17.39 \\
\hline 12 & -12 & 17.95 \\
\hline 13 & -13 & 18.47 \\
\hline 14 & -14 & 18.96 \\
\hline 15 & -15 & 19.40 \\
\hline 16 & -16 & 19.83 \\
\hline 17 & -17 & 20.23 \\
\hline 18 & -18 & 20.61 \\
\hline 19 & -19 & 20.97 \\
\hline 20 & -20 & 21.31 \\
\hline 21 & -21 & 21.64 \\
\hline 22 & -22 & 21.95 \\
\hline
\end{tabular}

Table 1: Cost and Benefit (in Points) for Producers and Consumers, Decentralized Meeting

decisions, Producers are informed of their own token holdings as well as the token holdings of their matched Consumer. Producers are then presented with their matched Consumer's proposal (amount of good requested and tokens offered in exchange). Producers must decide whether to: 1) "Accept" the Consumer's proposal, 2) "Reject" the Consumer's proposal or 3) "Make a Different Proposal"-see Figure 2. If a Producer clicks the Accept button, the proposed exchange takes place: the Producer produces the requested amount of the good, incurs a cost in points from doing so but receives the amount of tokens, if any, the Consumer offered in exchange. The Consumer receives a benefit in points from consumption of the amount of the good produced but loses any tokens offered to the Producer as part of the exchange. If the Producer clicks the Reject button, then no trade takes place: the token and point balances of both participants will remain unchanged. If the Producer clicks the Make a Different Proposal button, the Producer must further specify in the two input boxes associated with this choice a quantity of the good between 0 and 22 units inclusive that 


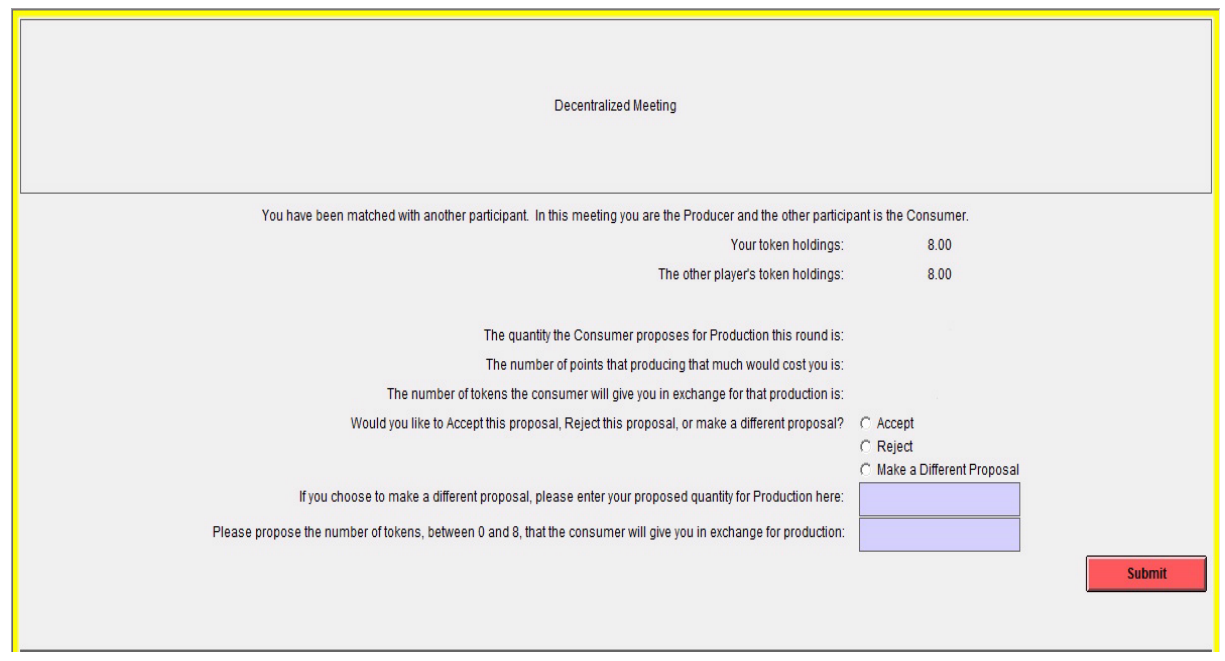

Figure 2: Initial Producer Decision Screen, Decentralized Meeting

$\mathrm{s} /$ he is willing to produce and a number of tokens up to the maximum number of tokens the Consumer has available that the Producer requests in exchange for producing the new proposed amount of the good. The Consumer is then presented with this new proposal and may 1) Accept it, in which case the exchange is implemented as described above, 2) Reject it, in which case no exchange takes place or 3) Make a Different Proposal to the Producer. If the Consumer makes a different proposal to the Producer's proposal, then the Producer must either 1) Accept or 2) Reject that proposal; following a maximum of three rounds of proposals, with the Consumer making the last proposal, there are no further opportunities to make proposals.

Once the results of the Decentralized Meeting (round 1) are revealed and any exchanges are implemented, we move on to the Centralized Meeting-round 2.

\section{Round 2: Centralized Meeting}

In the second round of a period, all 14 participants have the opportunity to interact in a single Centralized Meeting (there is no pairwise matching in the Centralized Meeting). Each participant brings with him/her the token holdings that s/he had at the end of round 1 (the Decentralized Meeting) after any exchanges have taken place in that round. In the Centralized Meeting, each participant can decide whether to 1) produce-and-sell units of a perishable good called "good X" in exchange for tokens, 2) use tokens to bid for (buy-andconsume) units of good X, 3) do both, or 4) do neither. The decision screen you face in the Centralized Meeting is shown in Figure 3.

Table 2 shows the points you can earn from producing-and-selling or from buying-andconsuming units of good X. For instance, if you choose to produce and sell 2 units of good $\mathrm{X}$ and you are able to sell those units (more on this below), then producing those two units 


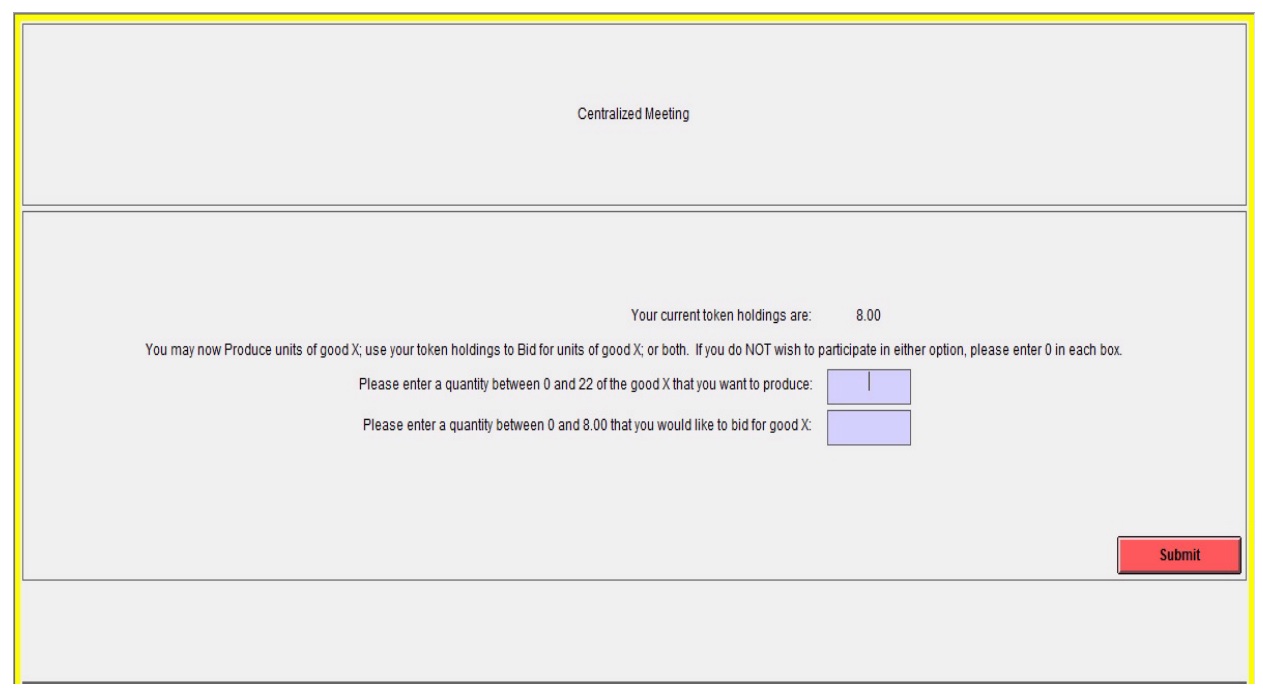

Figure 3: Decision Screen for All Participants in the Centralized Meeting.

will cost you 2 points. If you are able to buy and consume 7 units of good $\mathrm{X}$ (again, see below), this will give you a benefit of 7 points.

If you want to produce and sell units of good $\mathrm{X}$, then enter the quantity you will produce in the first input box. Call this quantity " $q$ ". You can produce and sell any quantity, $q$, of good X from 0 to 22 units inclusive (fractions allowed). If you do not want to produce and sell any units of good $\mathrm{X}$ then enter 0 in the first input box. If you want to use some of your current token holdings to buy and consume units of good $\mathrm{X}$, then enter the number of tokens you wish to bid in the second input box. Call the amount of your tokens bid, " $b$ ". You can bid any quantity of tokens up to the maximum number of tokens you currently have available at the start of the Centralized Meeting as shown on your decision screen. If you don't want to bid any of your tokens for units of good X then enter 0 in the second input box. When you are done making these choices, click the red submit button.

After all participants have clicked the red submit button, the computer program calculates the total amount of good $\mathrm{X}$ that all participants have offered to produce; call this: "Total Amount of Good X Produced." The program also calculates the total number of tokens bid toward units of good X by all participants; call this: "Total Amount of Tokens Bid for Good X." Then the program calculates the market price of good X in terms of tokens as follows:

If Total Amount of Good X Produced $>0$ and if Total Amount of Tokens Bid for Good $\mathrm{X}>0$, then the market price of good $\mathrm{X}, P$, is determined by:

$$
P=\frac{\text { Total Amount of Tokens Bid for Good X }}{\text { Total Amount of Good X Produced }}
$$

If Total Amount of Good X Produced $=0$ or if Total Amount of Tokens Bid for Good 


\begin{tabular}{|c|c|c|}
\hline $\begin{array}{c}\text { Quantity Produced, } q, \text { or } \\
\text { Quantity Bought, } b / P\end{array}$ & $\begin{array}{c}\text { Produce-and-Sell } \\
\text { Cost in Points } \\
\end{array}$ & $\begin{array}{c}\text { Buy-and-Consume } \\
\text { Benefit in Points }\end{array}$ \\
\hline 0 & 0 & 0 \\
\hline 1 & -1 & 1 \\
\hline 2 & -2 & 2 \\
\hline 3 & -3 & 3 \\
\hline 4 & -4 & 4 \\
\hline 5 & -5 & 5 \\
\hline 6 & -6 & 6 \\
\hline 7 & -7 & 7 \\
\hline 8 & -8 & 8 \\
\hline 9 & -9 & 9 \\
\hline 10 & -10 & 10 \\
\hline 11 & -11 & 11 \\
\hline 12 & -12 & 12 \\
\hline 13 & -13 & 13 \\
\hline 14 & -14 & 14 \\
\hline 15 & -15 & 15 \\
\hline 16 & -16 & 16 \\
\hline 17 & -17 & 17 \\
\hline 18 & -18 & 18 \\
\hline 19 & -19 & 19 \\
\hline 20 & $\overline{-20}$ & 20 \\
\hline 21 & -21 & 21 \\
\hline 22 & -22 & 22 \\
\hline
\end{tabular}

Table 2: Cost and Benefit (in Points) for Producers and Consumers, Centralized Meeting

$\mathrm{X}=0$ (or both are equal to 0 ), then $P=0$.

Notice that you do not know the value of $P$ when you are deciding whether to produce or bid tokens for units of good $\mathrm{X} ; P$ is determined only after all participants have made their Centralized Meeting decisions. Once the market price, $P$, is determined, if $P>0$ then individuals who participated in the Centralized Meeting earn points according to the formula:

$$
\text { Centralized Meeting payoff in points }=-q+b / P \text {. }
$$

The first term, $-q$, represents the cost to you of producing and selling $q$ units of good $\mathrm{X}$. The second term, $b / P$, represents the number of units good $\mathrm{X}$ you were able to buy and consume given your bid of $b$ tokens and the market determined price, $P$. In addition, if $P>0$, each individual who participated in the Centralized Meeting will see their own token 
balance adjusted as follows:

$$
\text { New Token Balance }=\text { Old Token Balance }+P q-b \text {. }
$$

Notice several things. First, if $-q+b / P$ is negative (equivalently, if $P q-b$ is positive ${ }^{1}$ ), so that you are a net seller of good $\mathrm{X}$, then you lose points from the Centralized Meeting according to the formula (1). However, at the same time, your new token balance increases relative to your old token balance by the positive amount $P q-b$ according to the formula (2). Second, if $-q+b / P$ is positive (equivalently, if $P q-b$ is negative) so that you are a net buyer of good $\mathrm{X}$, then you earn additional points from the Centralized Meeting according to formula (1). However, at the same time, your new token balance decreases relative to your old token balance by the negative amount $P q-b$ according to formula (2). Thus, if $P>0$, those who are net seller-producers of good X will leave the Centralized Meeting with higher token balances but with lower point totals, while those who are net buyer-consumers of good $\mathrm{X}$ will leave the Centralized Meeting with lower token balances but with higher point totals. Finally, note that if $P=0$, or if you do not produce or bid tokens for good $\mathrm{X}$ in the Centralized Meeting, then your point and token balances remain unchanged.

Players' new (or unchanged) token balances and point totals will carry over to the Decentralized Meeting of the next period of the sequence, if there is a next period, which depends on the random number drawn. If the sequence does not continue with a new period, then all participants' token balances are set to zero, and their point totals for the sequence are

final. Depending on the time available, a new sequence may then begin. At the beginning of each new sequence, each participant is given 8 tokens.

\section{Information}

After each round, all participants will be informed about their point totals and their token holdings. After round 1 (Decentralized Meeting) participants will also be informed about the point totals and the token holdings of the participant they were paired with. Nobody will ever be informed about the identity of the participant they are paired with. After round 2 (Centralized Meeting) you will see your token and point totals both for the Decentralized Meeting round 1, the Centralized Meeting round 2, the period (rounds 1 and 2 combined) and your cumulative point total for the current sequence. For your convenience, on each decision screen you will see a history of your decisions in prior rounds of the Decentralized Meeting (DM) or the Centralized Meeting (CM).

\section{Determination of your Earnings}

At the end of today's session, your point total from all sequences played, including the initial 20 points you were given at the start of the experiment, will be converted into dollars at the rate of 1 point $=\$ 0.30$.

\footnotetext{
${ }^{1}$ If $-q+b / P<0$, then $b / P<q$ or $b<P q$, so $P q-b>0$.
} 


\section{Summary}

1. You start with 20 points. You will play a number of sequences each consisting of an unknown number of periods. Your point total accumulates over all sequences.

2. All participants begin each sequence with 8 tokens. Tokens have no value in terms of points.

3. Each period in a sequence consists of two rounds.

\section{Round 1 Decentralized Meeting:}

i. Participants are randomly matched in pairs with one member of the pair randomly chosen to be the Consumer and the other chosen to be the Producer. Both roles are equally likely.

ii. Consumers decide how many units of a perishable good to request from the Producer they are matched with and how many tokens to offer the Producer for those units.

iii. Producers decide whether to accept, reject or make a different proposal to their matched Consumer.

iv. If the Producer has offered a different proposal, the Consumer can accept, reject or make a final, different proposal to the Producer.

v. If the Consumer has offered a final, different proposal, the Producer must accept or reject it; there is a maximum of three rounds of proposals.

vi. If at some point a proposal is accepted, the Consumer's point earnings are increased as in Table 1 . The Consumer's token holdings are decreased by the amount of tokens offered to the Producer. The Producer's point earnings are decreased by the cost of producing the amount of the good agreed upon. The Producer's token holdings are increased by the amount of tokens she receives from the Consumer in exchange for producing the good.

vii. Participants are informed about the point earnings and token holdings in their pair.

\section{Round 2 Centralized Meeting:}

i. All participants interact together in the Centralized Meeting to decide whether to produce-and-sell, buy-and-consume or not participate in the market for a perishable good X.

ii. Participants who decide to produce-and-sell enter a quantity, $q$, of units they wish to produce for sale. Participants who wish to buy-and-consume enter the number of their currently available tokens they wish to bid, $b$, toward units of good X.

iii. The market price, $P$, of good $\mathrm{X}$ is determined as the ratio of the total amount of tokens bid for good $\mathrm{X}$ to the total amount of good $\mathrm{X}$ produced. If there are no tokens bid or no amount of good $\mathrm{X}$ produced, then $P=0$. 
iv. If $P>0$, Centralized Meeting points are determined for each participant by the formula: Centralized Meeting points $=-q+b / P$. Each participant's token holdings are adjusted according to the formula: New token holdings $=$ Old token holdings $+P q-b$.

v. Participants are informed of the market price, $P$, and about their own Centralized Meeting point earnings (if any) and new token holdings (if a change has occurred).

4. At the end of each 2-round period, a number (integer) from 1-6 is randomly drawn and determines whether the sequence continues with another 2-round period. If a 1,2,3,4, or 5 is drawn the sequence continues. If a 6 is drawn, the sequence ends. Thus, there is a $5 / 6$ chance that a sequence continues and a $1 / 6$ chance that it ends.

5. If a sequence continues, then a new period begins. Token balances carry over from the end of the prior period and participants are randomly paired anew in the Decentralized Meeting (round 1) of the new period. If a sequence ends, then all participants' token balances are set equal to zero. Depending on the time available, a new sequence may begin. Each participant starts each new sequence with 8 tokens.

6. Points accumulate over all sequences. At the end of the session, each participant's cumulative point total will be converted into cash at the rate of 1 point $=\$ 0.30$. Token holdings can be carried over from round to round and period to period, but not from sequence to sequence.

\section{Questions?}

Now is the time for questions about these instructions. If you have a question, please raise your hand and an experimenter will come to you.

\section{Quiz}

Before we start, we would like you to answer a few questions that are meant to review the rules of today's experiment. The numbers that appear in these questions are for illustration purposes only; the actual numbers in the experiment may be different. When you are done answering these questions, raise your hand and an experimenter will check your answers.

1. How many rounds are there in each period?

2. Suppose it is period 2 of a sequence. What is the probability that the sequence continues with a period 3 ? Would your answer be any different if we replaced period 2 with period 12 and period 3 with period 13? Circle one: yes/no.

3. Can you choose whether you are a producer or consumer in the first round of a period, i.e., the Decentralized Meeting? 
4. Can you choose whether you are a producer/seller or buyer/consumer in the second round of a period, i.e. the Centralized Meeting?

5. Can you carry over token holdings from period to period? From sequence to sequence?

6. Suppose you start round 1 (Decentralized Meeting) holding 4 tokens. Suppose further that you are the Consumer. You propose to buy and consume 2 units in exchange for all 4 of your tokens and the Producer accepts your proposal.

a. What are your additional point earnings this round? (Use Table 1)

b. What are your token holdings at the beginning of round 2? (Centralized meeting)

7. Suppose you enter round 2 (Centralized Meeting) with 0 tokens. Suppose you choose to offer to produce $q=2$ units. You cannot bid for any units of good X as you have 0 tokens available. Thus you are a producer/seller of good X in the Centralized Meeting. After all participants have made their decisions, it turns out that the market price, $P=2$.

a. What are your additional point earnings this round? (Use Table 2)

b. What are your token holdings at the beginning of the next period if the random draw is a 3 ? If the random draw is a 6 , do your token holdings carry over to the next period? Circle one: yes / no

c. If the sequence continues and you are a Consumer in the round 1 of the next period, what is the maximum number of tokens that you can offer the Producer you are matched with in exchange for the good in the Decentralized Meeting?

8. Suppose you enter round 2 (Centralized Meeting) with 10 tokens. You choose to bid 5 of your tokens toward units of good $\mathrm{X}$ and choose not to produce any units of good X, i.e. $q=0$ and $b=5$. The market price turns out to be 1 .

a. How many units of good $\mathrm{X}$ were you able to buy and consume? What are your point earnings from the Centralized Meeting? (Use Table 2)

b. What are your new token holdings?

c. If the sequence continues and you are a Consumer in round 1 of the next period, what is the maximum number of tokens you can offer the Producer you are matched with in exchange for the good in the Decentralized Meeting?

9. True or False: Your point total from all sequences will be converted into money and paid to you in cash at the end of the session. Circle one: True False. 


\section{Instructions}

Welcome to this experiment in the economics of decision making. Funding for this experiment has been provided by the University of Pittsburgh. During today's session, you will be called upon to make a series of decisions. If you follow the instructions carefully and make good decisions, you can earn a considerable amount of money that will be paid to you in cash at the end of the experiment. Please, no talking for the duration of today's session.

We will first go over the instructions. When we are done, each of you will have to answer a few brief questions to ensure that everyone understands these instructions. You will also have time to ask clarifying questions. Then, you will begin making your decisions using the computer workstations.

\section{Overview}

There are 14 people participating in today's session. Each participant will make consuming, producing, buying or selling decisions in a number of sequences. Each sequence consists of an unknown number of periods. Each period consists of two rounds. At the end of each two-round period, the computer program will draw a random number, specifically, an integer in the set $\{1,2,3,4,5,6\}$. Each of these six numbers has an equal chance of being chosen; it is like rolling a six-sided die. The program will display the random number chosen on all participants' screens. If the random number is $1,2,3,4$ or 5 , the sequence will continue with another two-round period. If the random number is a 6 , the sequence will end. Thus the probability a sequence continues from one period to the next is $5 / 6$ and the probability it ends after each period is $1 / 6$. If a sequence ends, then depending on the time available, a new sequence will begin.

You will start today's experiment with an endowment of 20 points. Over the course of a sequence you may gain or lose points based on the decisions you make as will be explained in detail below. Your point total will carry over from one sequence to the next. Your final point total from all sequences played will determine your earnings for the experiment. Each point you earn is worth $\$ 0.30$.

\section{Timing and Pairing}

Recall that each period consists of two rounds. In the first round of each new period, the 14 participants will be randomly matched in 7 pairs and make decisions with one another in a Decentralized Meeting. In the second and final round of each period, all 14 participants will interact together in a Centralized Meeting. We will now describe what happens in each of these two rounds of a period.

\section{Round 1: Decentralized Meeting}

At the beginning of each Decentralized Meeting-the first round of each period-each participant is randomly paired with one other participant. All pairings are equally likely. In each 
pair, one participant is randomly chosen to be the Consumer and the other is the Producer. At the start of each Decentralized Meeting round, you are equally likely to be assigned either role; it is as though a coin flip determines whether you are a Producer or Consumer in each round. In the Decentralized Meeting, a perishable good is produced and can be traded. This good is "perishable" because it cannot be carried over into any other round or period. Producers incur a cost in points for producing some quantity of this perishable good which is subtracted from their point total and Consumers receive a benefit in points from consuming some quantity of the perishable good which is added to their point total. Table 1 summarizes how costs and benefits are related to your point earnings. For example, if you are a Producer and agree to produce 2 units of the good, you incur a production cost of 2 points. If you are a Consumer and you succeed in consuming 7 units of the good, you get a benefit of 14.56 points.

\begin{tabular}{|c|c|c|}
\hline Quantity & Producer's Cost in Points & Consumer's Benefit in Points \\
\hline 0 & 0 & 0.00 \\
\hline 1 & -1 & 4.85 \\
\hline 2 & -2 & 7.69 \\
\hline 3 & -3 & 9.70 \\
\hline 4 & -4 & 11.27 \\
\hline 5 & -5 & 12.54 \\
\hline 6 & -6 & 13.62 \\
\hline 7 & -7 & 14.56 \\
\hline 8 & -8 & 15.38 \\
\hline 9 & -9 & 16.12 \\
\hline 10 & -10 & 16.78 \\
\hline 11 & -11 & 17.39 \\
\hline 12 & -12 & 17.95 \\
\hline 13 & -13 & 18.47 \\
\hline 14 & -14 & 18.96 \\
\hline 15 & -15 & 19.40 \\
\hline 16 & -16 & 19.83 \\
\hline 17 & -17 & 20.23 \\
\hline 18 & -18 & 20.61 \\
\hline 19 & -19 & 20.97 \\
\hline 20 & -20 & 21.31 \\
\hline 21 & -21 & 21.64 \\
\hline 22 & -22 & 21.95 \\
\hline
\end{tabular}

Table 1: Cost and Benefit (in Points) for Producers and Consumers, Decentralized Meeting Consumers move first and must decide on how many units of the perishable good they 
Decentralized Meeting

You have been matched with another participant. In this meeting you are the Consumer and the other participant is the Producer Please enter a quantity between 0 and 22 of the good you want from the Producer with whom you are matched this round.

Figure 1: Initial Consumer Decision Screen, Decentralized Meeting.

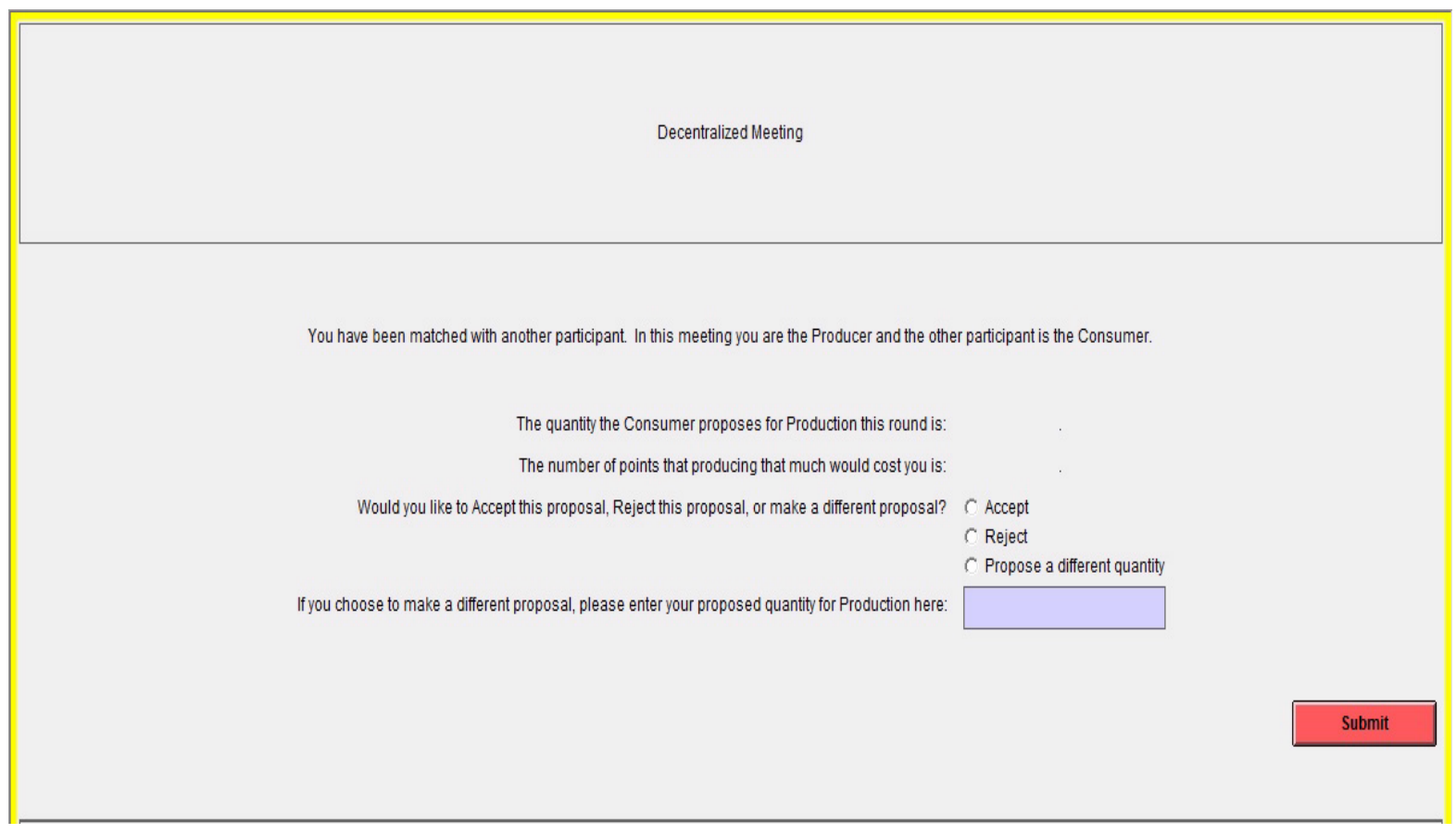

Figure 2: Initial Producer Decision Screen, Decentralized Meeting 
want their matched Producer to produce for them-see Figure 1. Consumers can request any amount of the good between 0 and 22 units inclusive (fractions allowed). After all Consumers have made their decisions, Producers are then presented with their matched Consumer's proposal (amount of good requested). Producers must decide whether to: 1) "Accept" the Consumer's proposal, 2) "Reject" the Consumer's proposal or 3) "Make a Different Proposal"-see Figure 2. If the Producer clicks the Accept button, the proposed exchange takes place: the Producer produces the requested amount of the good and incurs a cost in points from doing so. The Consumer receives a benefit in points from consumption of the amount of the good produced. If the Producer clicks the Reject button, then no trade takes place: the point balances of both participants will remain unchanged. If the Producer clicks the Make a Different Proposal button, the Producer must further specify in the input box associated with this choice a quantity of the good between 0 and 22 units inclusive that $\mathrm{s} /$ he is willing to produce for the Consumer. The Consumer is then presented with this new proposal and may 1) Accept it, in which case the exchange is implemented as described above, 2) Reject it, in which case no exchange takes place or 3) Make a Different Proposal to the Producer. If the Consumer makes a different proposal to the Producer's proposal, then the Producer must either 1) Accept or 2) Reject that proposal; following a maximum of three rounds of proposals, with the Consumer making the last proposal, there are no further opportunities to make proposals.

Once the results of the Decentralized Meeting (round 1) are revealed and any exchanges are implemented, we move on to the Centralized Meeting-round 2.

\section{Round 2: Centralized Meeting}

In the second round of a period, all 14 participants have the opportunity to interact in a single Centralized Meeting (there is no pairwise matching in the Centralized Meeting). In the Centralized Meeting, each participant can decide whether to produce-and-sell units of a perishable good called "good X." Participants who choose to produce-and-sell units of good $\mathrm{X}$ can further choose to buy-and-consume units of good X. Participants can also choose not to produce or buy any units of good X.

The first decision screen you face in the Centralized Meeting is shown in Figure 3. There you are asked how many units of good $\mathrm{X}$ you would like to offer to produce-and-sell. You can enter any number between 0 and 22 units inclusive (fractions allowed). Call this quantity " $q$ ". If you do not want to produce and sell any units of good $\mathrm{X}$ then enter 0 in the first input box. After you have entered your choice on the first Centralized Meeting decision screen click the red submit button.

If you offer to produce $q>0$ units of good $\mathrm{X}$, you may be able to sell those units of good $\mathrm{X}$ at the market price, $P$, to buyers of good $\mathrm{X}$ if there is some demand for good $\mathrm{X}$ (as explained below). After all participants have chosen how many units of good $\mathrm{X}$ to offer to produce, those participants who entered $q>0$ units of good X are asked on a second, Centralized Meeting decision screen whether they would like to bid to buy-and-consume any units of good X -see Figure 4. Each participant can bid to buy-and-consume any number of 
Figure 3: Production of Good X Decision Screen, Centralized Meeting.

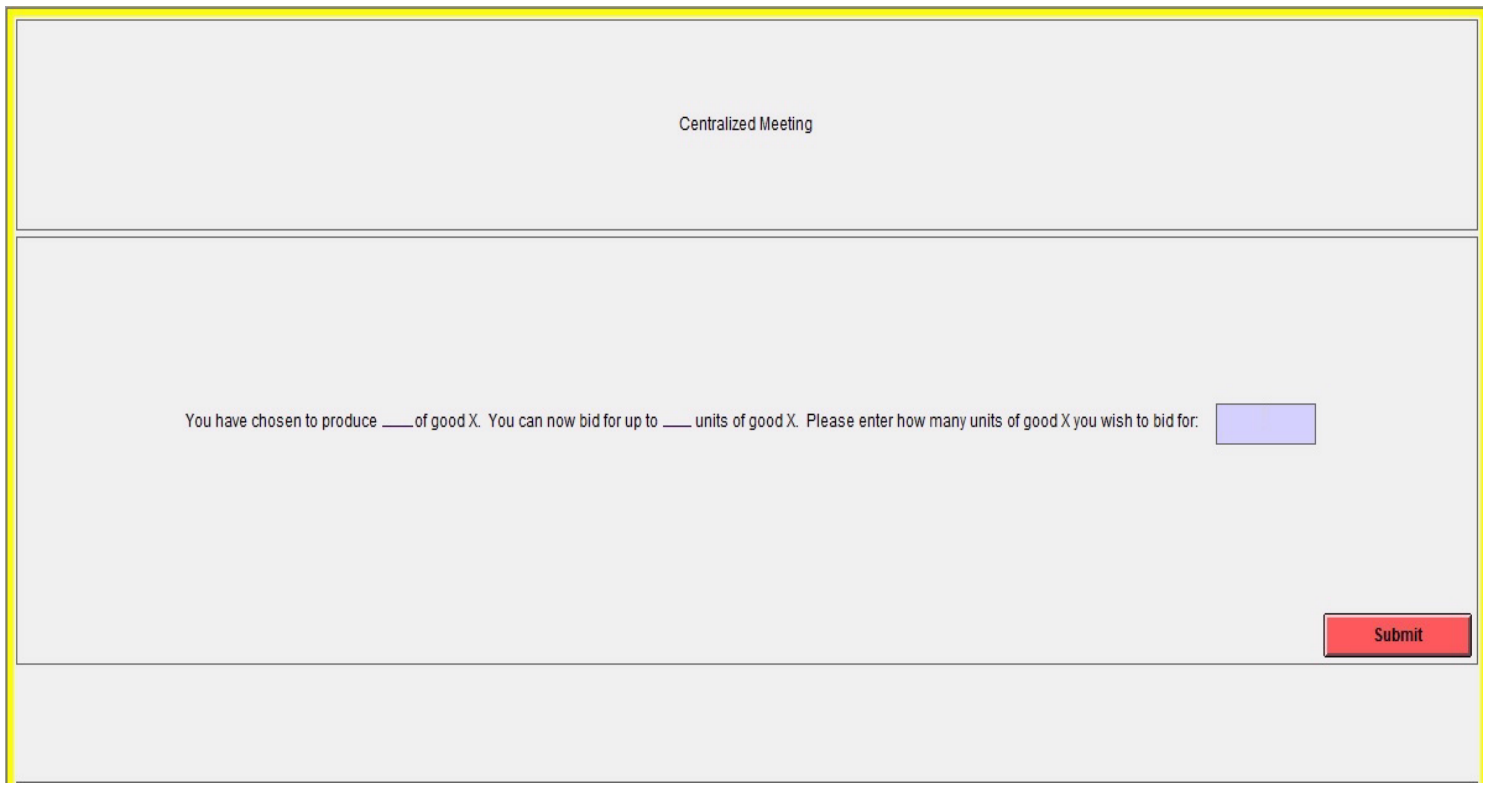

Figure 4: Bid for Good X Decision Screen, Centralized Meeting. 


\begin{tabular}{|c|c|c|}
\hline $\begin{array}{c}\text { Quantity Produced, } q, \text { or } \\
\text { Quantity Bought, } b / P\end{array}$ & $\begin{array}{c}\text { Produce-and-Sell } \\
\text { Cost in Points } \\
\end{array}$ & $\begin{array}{c}\text { Buy-and-Consume } \\
\text { Benefit in Points }\end{array}$ \\
\hline 0 & 0 & 0 \\
\hline 1 & -1 & 1 \\
\hline 2 & -2 & 2 \\
\hline 3 & -3 & 3 \\
\hline 4 & -4 & 4 \\
\hline 5 & -5 & 5 \\
\hline 6 & -6 & 6 \\
\hline 7 & -7 & 7 \\
\hline 8 & -8 & 8 \\
\hline 9 & -9 & 9 \\
\hline 10 & -10 & 10 \\
\hline 11 & -11 & 11 \\
\hline 12 & -12 & 12 \\
\hline 13 & -13 & 13 \\
\hline 14 & -14 & 14 \\
\hline 15 & -15 & 15 \\
\hline 16 & -16 & 16 \\
\hline 17 & -17 & 17 \\
\hline 18 & -18 & 18 \\
\hline 19 & -19 & 19 \\
\hline 20 & $\overline{-20}$ & 20 \\
\hline 21 & -21 & 21 \\
\hline 22 & -22 & 22 \\
\hline
\end{tabular}

Table 2: Cost and Benefit (in Points) for Producers and Consumers, Centralized Meeting

units of good X between 0 and $q$ inclusive (fractions allowed), where $q$ is again the quantity of good X they chose to produce-and-sell. Call the amount you offer to bid to buy-and-consume units of good X, " $b$ ", so that $0 \leq b \leq q$. If you do not want to bid to buy and consume any units of good $\mathrm{X}$ then enter 0 in the input box of the second Centralized Meeting screen. When you are done making this choice, click the red submit button.

Table 2 shows the points that you can earn from producing-and-selling or from buyingand-consuming units of good X. For instance, if you choose to produce and sell 2 units of good $\mathrm{X}$ and you are able to sell those units (more on this below), then producing those two units will cost you 2 points. If you are able to buy and consume 7 units of good X (again, see below), this will give you a benefit of 7 points.

After all participants have clicked the red submit button, the computer program calculates the total amount of good $\mathrm{X}$ that all participants have offered to produce and sell; call 
this: "Total Amount of Good X Produced." The program also calculates the total number of units of good X that all participants have bid to buy and consume; call this: "Total Amount Bid for Good X." Then the program calculates the market price of good X as follows:

If Total Amount of Good X Produced $>0$ and Total Amount Bid for Good X >0, then the market price of good $\mathrm{X}, P$, is determined by:

$$
P=\frac{\text { Total Amount Bid for Good X }}{\text { Total Amount of Good X Produced }}
$$

If Total Amount of Good X Produced $=0$ or Total Amount Bid for Good X $=0$ (or both are equal to 0 ), then $P=0$.

Notice that you do not know the value of $P$ when you are deciding whether to produce or bid for units of good $\mathrm{X} ; P$ is determined only after all participants have made their Centralized Meeting decisions. Once the market price, $P$, is determined, if $P>0$ then individuals who participated in the Centralized Meeting earn points according to the formula:

$$
\text { Centralized Meeting payoff in points }=-q+b / P \text {. }
$$

The first term, $-q$, represents the cost to you of the $q$ units of good $\mathrm{X}$ that you offered to produce and sell. The second term, $b / P$, represents the number of units of good $\mathrm{X}$ that you were able to buy and consume given your bid, $b$, and the market determined price, $P$.

Notice several things. First, if $-q+b / P$ is negative (equivalently, if $P q-b$ is positive ${ }^{1}$ ), so that you are a net seller of good $\mathrm{X}$, then you lose points from the Centralized Meeting according to formula (1). Second, if $-q+b / P$ is positive (equivalently, if $P q-b$ is negative) so that you are a net buyer of good $\mathrm{X}$, then you earn additional points from the Centralized Meeting according to formula (1). Thus, if $P>0$, those who are net seller-producers of good $\mathrm{X}$ will leave the Centralized Meeting with lower point totals, while those who are net buyerconsumers of good $\mathrm{X}$ will leave the Centralized Meeting with higher point totals. Finally, note that if $P=0$, or if you do not produce or bid for good $\mathrm{X}$ in the Centralized Meeting, then your point balance remains unchanged.

Players' new (or unchanged) point totals will carry over to the Decentralized Meeting of the next period of the sequence, if there is a next period, which depends on the random number drawn. If the sequence does not continue with a new period, then all participants' point totals for the sequence are final. Depending on the time available, a new sequence may then begin.

\section{Information}

After each Decentralized Meeting round, all participants will be informed about their point earnings and those of the participant with whom they were paired. Nobody will ever be informed about the identity of the participant with whom they were paired in any round of this experiment. Following round 2 (Centralized Meeting) you will see your point totals

\footnotetext{
${ }^{1}$ If $-q+b / P<0$, then $b / P<q$ or $b<P q$, so $P q-b>0$.
} 
both for the Decentralized Meeting round 1, the Centralized Meeting round 2, the period (rounds 1 and 2 combined) and your cumulative point total for the current sequence. For your convenience, on each decision screen you will see a history of your decisions in prior rounds of the Decentralized Meeting (DM) or the Centralized Meeting (CM).

\section{Determination of your Earnings}

At the end of today's session, your point total from all sequences played, including the initial 20 points you were given at the start of the experiment, will be converted into dollars at the rate of 1 point $=\$ 0.30$.

\section{Summary}

1. You start with 20 points. You will play a number of sequences each consisting of an unknown number of periods. Your point total accumulates over all sequences.

2. Each period in a sequence consists of two rounds.

\section{Round 1 Decentralized Meeting:}

i. Participants are randomly matched in pairs with one member of the pair randomly chosen to be the Consumer and the other chosen to be the Producer. Both roles are equally likely.

ii. Consumers decide how many units of a perishable good to request from the Producer with whom they are paired.

iii. Producers decide whether to accept, reject or make a different proposal to their matched Consumer.

iv. If the Producer has offered a different proposal, the Consumer can accept, reject or make a final, different proposal to the Producer.

v. If the Consumer has offered a final, different proposal, the Producer must accept or reject it; there is a maximum of three rounds of proposals.

vi. If at some point a proposal is accepted, the Consumer's point earnings are increased as in Table 1. The Producer's point earnings are decreased by the cost of producing the amount of the good agreed upon.

vii. Participants are informed about the point earnings in their pair.

\section{Round 2 Centralized Meeting:}

i. All participants interact together in the Centralized Meeting to decide whether to produce-and-sell, buy-and-consume or not participate in the market for a perishable good X.

ii. Participants who choose to produce-and-sell enter a quantity, $q$, of units they wish to produce for sale. Participants who enter a positive quantity $q>0$ are then asked whether they would like to bid to buy-and-consume units of 
good X. A participant's bid $b$ can be any amount between 0 and $q$, inclusive, where $q$ is the quantity they offered to produce and sell of good X.

iii. The market price, $P$, of good $\mathrm{X}$ is determined as the ratio of the total amount bid for good $\mathrm{X}$ to the total amount of good $\mathrm{X}$ produced. If there are no bids (demand) for good $\mathrm{X}$ or no amount of good X produced (supply) then $P=0$.

iv. If $P>0$, Centralized Meeting points are determined for each participant by the formula: Centralized Meeting points $=-q+b / P$. If $P=0$, there is no market for good $\mathrm{X}$ and all participants earn 0 points from the Centralized Meeting.

v. Participants are informed of the market price, $P$, and about their own Centralized Meeting point earnings (if any).

3. At the end of each 2-round period, a number (integer) from 1-6 is randomly drawn and determines whether the sequence continues with another 2-round period. If a 1,2,3,4, or 5 is drawn the sequence continues. If a 6 is drawn, the sequence ends. Thus, there is a $5 / 6$ chance that a sequence continues and a $1 / 6$ chance that it ends.

4. If a sequence continues, then a new period begins. Point balances carry over from the end of the prior period and participants are randomly paired anew in the Decentralized Meeting (round 1) of the new period. If a sequence ends, then depending on the time available, a new sequence may begin.

5. Points accumulate over all sequences. At the end of the session, each participant's cumulative point total will be converted into cash at the rate of 1 point $=\$ 0.30$.

\section{Questions?}

Now is the time for questions about these instructions. If you have a question, please raise your hand and an experimenter will come to you.

\section{Quiz}

Before we start, we would like you to answer a few questions that are meant to review the rules of today's experiment. The numbers that appear in these questions are for illustration purposes only; the actual numbers in the experiment may be different. When you are done answering these questions, raise your hand and an experimenter will check your answers.

1. How many rounds are there in each period?

2. Suppose it is period 2 of a sequence. What is the probability that the sequence continues with a period 3 ? Would your answer be any different if we replaced period 2 with period 12 and period 3 with period 13 ? Circle one: yes/no. 
3. Can you choose whether you are a producer or consumer in the first round of a period, i.e., the Decentralized Meeting?

4. Can you choose whether you are a producer/seller or buyer/consumer in the second round of a period, i.e. the Centralized Meeting?

5. Suppose in the Decentralized Meeting that you are the Consumer. You propose that the producer produce 2 units of the perishable good and the Producer accepts your proposal.

a. What are your additional point earnings this round? (Use Table 1)

b. How many points does it cost the Producer for agreeing to your proposal? (Use Table 1)

6. Suppose that in the Centralized Meeting you offered to produce and sell $q=4$ units and you bid $b=1$ to buy and consume units of good X. After all participants have made their decisions, it turns out that the market price, $P=1 / 2$.

a. How many points does it cost you to produce and sell the 4 units? (Use Table 2)

b. How many units of good $\mathrm{X}$ were you able to buy-and-consume with your bid of 1 ? (use the formula $b / P$ ) How many points is this worth? (Use Table 2)

c. What are your total points from the Centralized meeting? (use the formula: $-q+$ $b / P)$

7. Suppose that in the Centralized Meeting you offered to produce and sell $q=5$ units and you bid $b=5$ to buy and consume units of good X. After all participants have made their decisions, it turns out that the market price, $P=1$.

a. How many points does it cost you to produce and sell the 5 units? (Use Table 2)

b. How many units of good $\mathrm{X}$ were you able to buy-and-consume with your bid of 5 ? (use the formula $b / P$ ) How many points is this worth? (Use Table 2)

c. What are your total points from the Centralized meeting? (use the formula: $-q+$ $b / P)$

8. True or False: Your point total from all sequences will be converted into money and paid to you in cash at the end of the session. Circle one: True False. 


\section{Instructions}

Welcome to this experiment in the economics of decision making. Funding for this experiment has been provided by the University of Pittsburgh. During today's session, you will be called upon to make a series of decisions. If you follow the instructions carefully and make good decisions, you can earn a considerable amount of money that will be paid to you in cash at the end of the experiment. Please, no talking for the duration of today's session.

We will first go over the instructions. When we are done, each of you will have to answer a few brief questions to ensure that everyone understands these instructions. You will also have time to ask clarifying questions. Then, you will begin making your decisions using the computer workstations.

\section{Overview}

There are 14 people participating in today's session. Each participant will make consuming or producing decisions in a number of sequences. Each sequence consists of an unknown number of periods. Prior to the start of each new period, the computer program draws a number, specifically, an integer in the set $\{1,2,3,4,5,6\}$. Each of these six numbers has an equal chance of being chosen; it is like rolling a six-sided die. The program will display the random number chosen on all participants' screens. If the random number is 1,2,3,4 or 5, the sequence will continue with another period. If the random number is a 6 , the sequence will end. Thus the probability a sequence continues from one period to the next is $5 / 6$ and the probability it ends after each period is $1 / 6$. If a sequence ends, then depending on the time available, a new sequence will begin.

You will start today's experiment with an endowment of 20 points. Over the course of a sequence you may gain or lose points based on the decisions you make as will be explained in detail below. Your point total will carry over from one sequence to the next. Your final point total from all sequences played will determine your earnings for the experiment. Each point you earn is worth $\$ 0.30$.

\section{Detailed Description of a Period}

In each new period, the 14 participants will be randomly matched in 7 pairs and make decisions with one another. All pairings are equally likely. In each pair, one participant is randomly chosen to be the Consumer and the other is the Producer. At the start of each period you are equally likely to be assigned either role; it is as though a coin flip determines whether you are a Producer or Consumer in each period. After you have been randomly paired and your roles randomly assigned you will have to decide on production and consumption of a perishable good. This good is "perishable" because it cannot be carried over into any other period. Producers incur a cost in points for producing some quantity of this perishable good which is subtracted from their point total and Consumers receive a benefit in points from consuming some quantity of the perishable good which is added 
to their point total. Table 1 summarizes how costs and benefits are related to your point earnings. For example, if you are a Producer and agree to produce 2 units of the good, then you incur a production cost of 2 points. If you are a Consumer and you succeed in consuming 7 units of the good, then you get a benefit of 14.56 points.

\begin{tabular}{|c|c|c|}
\hline Quantity & Producer's Cost in Points & Consumer's Benefit in Points \\
\hline 0 & 0 & $\begin{array}{l}0.00 \\
\end{array}$ \\
\hline 1 & -1 & 4.85 \\
\hline 2 & -2 & 7.69 \\
\hline 3 & -3 & 9.70 \\
\hline 4 & -4 & 11.27 \\
\hline 5 & -5 & 12.54 \\
\hline 6 & -6 & 13.62 \\
\hline 7 & -7 & 14.56 \\
\hline 8 & -8 & 15.38 \\
\hline 9 & -9 & 16.12 \\
\hline 10 & -10 & 16.78 \\
\hline 11 & -11 & 17.39 \\
\hline 12 & -12 & 17.95 \\
\hline 13 & -13 & 18.47 \\
\hline 14 & -14 & 18.96 \\
\hline 15 & -15 & 19.40 \\
\hline 16 & -16 & 19.83 \\
\hline 17 & -17 & 20.23 \\
\hline 18 & -18 & 20.61 \\
\hline 19 & -19 & 20.97 \\
\hline 20 & -20 & 21.31 \\
\hline 21 & -21 & 21.64 \\
\hline 22 & -22 & 21.95 \\
\hline
\end{tabular}

Table 1: Cost and Benefit (in Points) for Producers and Consumers, Decentralized Meeting

Consumers move first and must decide on how many units of the perishable good they want their matched Producer to produce for them-see Figure 1. Consumers can request any amount of the good between 0 and 22 units inclusive (fractions allowed). After all Consumers have made their decisions, Producers are then presented with their matched Consumer's proposal (amount of good requested). Producers must decide whether to: 1) "Accept" the Consumer's proposal, 2) "Reject" the Consumer's proposal or 3) "Make a Different Proposal"-see Figure 2. If the Producer clicks the Accept button, the proposed exchange takes place: the Producer produces the requested amount of the good and incurs a cost in points from doing so. The Consumer receives a benefit in points from consumption 
Period 1, Sequence 1

You have been matched with another participant. In this meeting you are the Consumer and the other participant is the Producer Please enter a quantity between 0 and 22 of the good you want from the Producer with whom you are matched this round.

Figure 1: Consumer Decision Screen

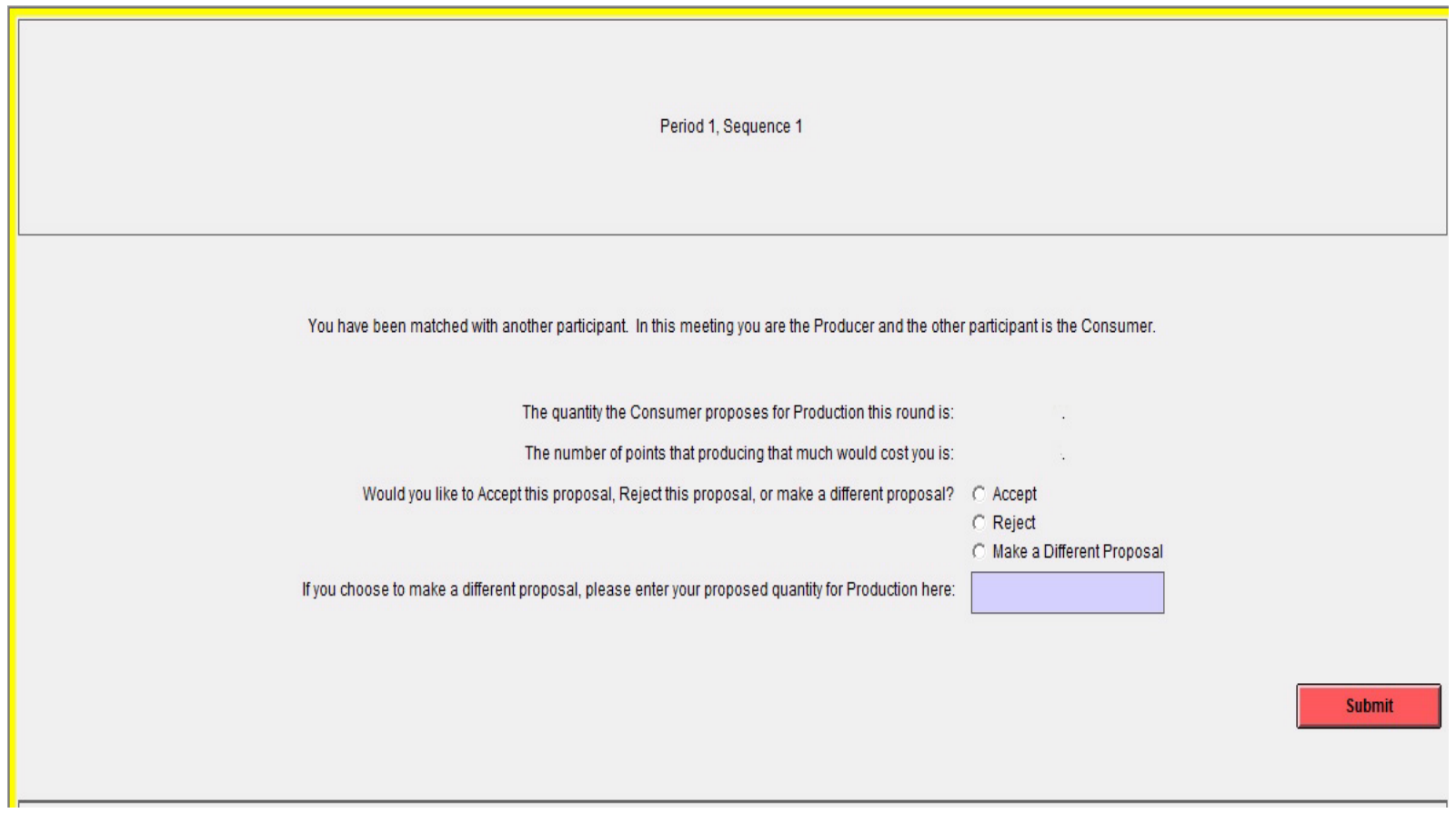

Figure 2: Producer Decision Screen 
of the amount of the good produced. If the Producer clicks the Reject button, then no trade takes place: the point balances of both participants will remain unchanged. If the Producer clicks the Make a Different Proposal button, the Producer must further specify in the input box associated with this choice a quantity of the good between 0 and 22 units inclusive that $\mathrm{s} /$ he is willing to produce for the Consumer. The Consumer is then presented with this new proposal and may 1) Accept it, in which case the exchange is implemented as described above, 2) Reject it, in which case no exchange takes place or 3) Make a Different Proposal to the Producer. If the Consumer makes a different proposal to the Producer's proposal, then the Producer must either 1) Accept or 2) Reject that proposal; following a maximum of three rounds of proposals, with the Consumer making the last proposal, there are no further opportunities to make proposals.

Once decisions have been made for the period, that period is over and the results of those decisions are revealed to each member of the pair. Players' new (or unchanged) point totals will carry over to the next period of the sequence, if there is a next period, which depends on the random number drawn. If the sequence does not continue with a new period, then all participants' point totals for the sequence are final. Depending on the time available, a new sequence may then begin.

\section{Information}

After each period, all participants will be informed about their point earnings and those of the participant with whom they were paired. Nobody will ever be informed about the identity of the participant with whom they were paired in any period of this experiment. Following the first period, you will see a history of your decisions, point earnings and cumulative point earnings in prior periods of the sequence.

\section{Determination of your Earnings}

At the end of today's session, your point total from all sequences played, including the initial 20 points you were given at the start of the experiment, will be converted into dollars at the rate of 1 point $=\$ 0.30$.

\section{Summary}

1. You start with 20 points. You will play a number of sequences each consisting of an unknown number of periods. Your point total accumulates over all sequences.

2. Each period proceeds as follows:

(a) Participants are randomly matched in pairs with one member of the pair randomly chosen to be the Consumer and the other chosen to be the Producer. Both roles are equally likely. 
(b) Consumers decide how many units of a perishable good to request from the Producer with whom they are paired.

(c) Producers decide whether to accept, reject or make a different proposal to their matched Consumer.

(d) If the Producer has offered a different proposal, the Consumer can accept, reject or make a final, different proposal to the Producer.

(e) If the Consumer has offered a final, different proposal, the Producer must accept or reject it; there is a maximum of three rounds of proposals.

(f) If at some point a proposal is accepted, the Consumer's point earnings are increased as in Table 1. The Producer's point earnings are decreased by the cost of producing the amount of the good agreed upon.

(g) Participants are informed about the point earnings in their pair.

3. At the end of each period, a number (integer) from 1-6 is randomly drawn and determines whether the sequence continues with another period. If a $1,2,3,4$, or 5 is drawn the sequence continues. If a 6 is drawn, the sequence ends. Thus, there is a $5 / 6$ chance that a sequence continues with another period and a $1 / 6$ chance that it ends.

4. If a sequence continues, then a new period begins. Point balances carry over from the end of the prior period and participants are randomly paired anew in the new period. If a sequence ends, then point balances for that sequence are final. Depending on the time available, a new sequence may begin.

5. Points accumulate over all sequences. At the end of the session, each participant's cumulative point total will be converted into cash at the rate of 1 point $=\$ 0.30$.

\section{Questions?}

Now is the time for questions about these instructions. If you have a question, please raise your hand and an experimenter will come to you.

\section{Quiz}

Before we start, we would like you to answer a few questions that are meant to review the rules of today's experiment. The numbers that appear in these questions are for illustration purposes only; the actual numbers in the experiment may be different. When you are done answering these questions, raise your hand and an experimenter will check your answers.

1. Suppose it is period 2 of a sequence. What is the probability that the sequence continues with a period 3 ? Would your answer be any different if we replaced period 2 with period 12 and period 3 with period 13 ? Circle one: yes no. 
2. Can you choose whether you are a producer or consumer in each period? Circle one: yes no.

3. What is the maximum number of rounds of proposals that can be made in each period?

4. Suppose that you are the Consumer. You propose that the Producer produce 2 units of the perishable good and the Producer accepts your proposal.

a. What are your point earnings this period? (Use Table 1)

b. How many points does it cost the Producer for agreeing to your proposal? (Use Table 1)

5. True or False: Your point total from all sequences will be converted into money and paid to you in cash at the end of the session. Circle one: True False. 


\section{Instructions}

You will face a sequence of 10 decisions. Each decision is a paired choice between two options, labeled "Option A" and "Option B". For each decision you must choose either Option A or Option B. You do this by clicking next to the radio button corresponding to your choice on the computer screen. After making your choice, please also record it on the attached record sheet under the appropriate headings.

The sequence of 10 decisions you will face are as follows:

\begin{tabular}{|c|c|c|}
\hline Decision & Option A & Option B \\
\hline 1 & $\begin{array}{lll}\text { Receive } \$ 6.00 & 10 \text { out of } 100 \text { draws OR } \\
\text { Receive } \$ 4.80 & 90 \text { out of } 100 \text { draws } \\
\end{array}$ & $\begin{array}{ll}\text { Receive } \$ 11.55 & 10 \text { out of } 100 \text { draws OR } \\
\text { Receive } \$ 0.30 & 90 \text { out of } 100 \text { draws }\end{array}$ \\
\hline 2 & $\begin{array}{lll}\text { Receive } \$ 6.00 & 20 \text { out of } 100 \text { draws OR } \\
\text { Receive } \$ 4.80 & 80 \text { out of } 100 \text { draws }\end{array}$ & $\begin{array}{lll}\text { Receive } \$ 11.55 & 20 \text { out of } 100 \text { draws OR } \\
\text { Receive } \$ 0.30 & 80 \text { out of } 100 \text { draws }\end{array}$ \\
\hline 3 & $\begin{array}{lll}\text { Receive } \$ 6.00 & 30 \text { out of } 100 \text { draws OR } \\
\text { Receive } \$ 4.80 & 70 \text { out of } 100 \text { draws } \\
\end{array}$ & $\begin{array}{lll}\text { Receive } \$ 11.55 & 30 \text { out of } 100 \text { draws OR } \\
\text { Receive } \$ 0.30 & 70 \text { out of } 100 \text { draws }\end{array}$ \\
\hline 4 & $\begin{array}{lll}\text { Receive } \$ 6.00 & 40 \text { out of } 100 \text { draws OR } \\
\text { Receive } \$ 4.80 & 60 \text { out of } 100 \text { draws }\end{array}$ & $\begin{array}{lll}\text { Receive } \$ 11.55 & 40 \text { out of } 100 \text { draws OR } \\
\text { Receive } \$ 0.30 & 60 \text { out of } 100 \text { draws }\end{array}$ \\
\hline 5 & $\begin{array}{lll}\text { Receive } \$ 6.00 & 50 \text { out of } 100 \text { draws OR } \\
\text { Receive } \$ 4.80 & 50 \text { out of } 100 \text { draws }\end{array}$ & $\begin{array}{lll}\text { Receive } \$ 11.55 & 50 \text { out of } 100 \text { draws OR } \\
\text { Receive } \$ 0.30 & 50 \text { out of } 100 \text { draws }\end{array}$ \\
\hline 6 & $\begin{array}{lll}\text { Receive } \$ 6.00 & 60 \text { out of } 100 \text { draws OR } \\
\text { Receive } \$ 4.80 & 40 \text { out of } 100 \text { draws } \\
\end{array}$ & $\begin{array}{lll}\text { Receive } \$ 11.55 & 60 \text { out of } 100 \text { draws OR } \\
\text { Receive } \$ 0.30 & 40 \text { out of } 100 \text { draws } \\
\end{array}$ \\
\hline 7 & $\begin{array}{lll}\text { Receive } \$ 6.00 & 70 \text { out of } 100 \text { draws OR } \\
\text { Receive } \$ 4.80 & 30 \text { out of } 100 \text { draws } \\
\end{array}$ & $\begin{array}{lll}\text { Receive } \$ 11.55 & 70 \text { out of } 100 \text { draws OR } \\
\text { Receive } \$ 0.30 & 30 \text { out of } 100 \text { draws } \\
\end{array}$ \\
\hline 8 & $\begin{array}{lll}\text { Receive } \$ 6.00 & 80 \text { out of } 100 \text { draws OR } \\
\text { Receive } \$ 4.80 & 20 \text { out of } 100 \text { draws } \\
\end{array}$ & $\begin{array}{lll}\text { Receive } \$ 11.55 & 80 \text { out of } 100 \text { draws OR } \\
\text { Receive \$ } 0.30 & 20 \text { out of } 100 \text { draws } \\
\end{array}$ \\
\hline 9 & $\begin{array}{lll}\text { Receive } \$ 6.00 & 90 \text { out of } 100 \text { draws OR } \\
\text { Receive } \$ 4.80 & 10 \text { out of } 100 \text { draws } \\
\end{array}$ & $\begin{array}{ll}\text { Receive } \$ 11.55 & 90 \text { out of } 100 \text { draws OR } \\
\text { Receive } \$ 0.30 & 10 \text { out of } 100 \text { draws } \\
\end{array}$ \\
\hline 10 & $\begin{array}{l}\text { Receive } \$ 6.00100 \text { out of } 100 \text { draws OR } \\
\text { Receive } \$ 4.80 \quad 0 \text { out of } 100 \text { draws }\end{array}$ & $\begin{array}{l}\text { Receive } \$ 11.55100 \text { out of } 100 \text { draws OR } \\
\text { Receive } \$ 0.30 \quad 0 \text { out of } 100 \text { draws }\end{array}$ \\
\hline
\end{tabular}

After you have made all 10 decisions, the computer program will randomly select 1 of the 10 decisions and your choice for that decision will be used to determine your payoff. All 10 decisions have the same chance of being chosen.

Notice that for each decision, the two options describe two different amounts of money you can receive, depending on a random draw. The random draw will be made by the computer and will be a number (integer) from 1 to 100 inclusive. Consider Decision 1. If you choose Option A, then you receive $\$ 6.00$ if the random number drawn is 10 or less, that is, in 10 out of 100 possible random draws made by the computer, or 10 percent of the time, while you receive $\$ 4.80$ if the random number is between 11 and 100, that is in 90 out of 100 possible random draws made by the computer, or 90 percent of the time. If you choose Option $\mathrm{B}$, then you receive $\$ 11.55$ if the random number drawn is 10 or less, that is, in 10 out of 100 possible random draws made by the computer, while you receive $\$ 0.30$ if the random number is between 11 and 100 , that is in 90 out of 100 possible random draws made by the computer, or 90 percent of the time. Other decisions are similar, except that your chances of receiving the higher payoff for each option increase. Notice that all decisions except decision 10 involve random draws. For decision 10, you face a certain (100 percent) chance of \$6.00 if you choose Option A or a certain (100 percent) chance of $\$ 11.55$ if you choose Option B. 
Even though you make 10 decisions, only ONE of these decisions will be used to determine your earnings from this experiment. All 10 decisions have an equal chance of being chosen to determine your earnings. You do not know in advance which of these decisions will be selected.

Consider again decision 1 . This will appear to you on your computer screen as follows:

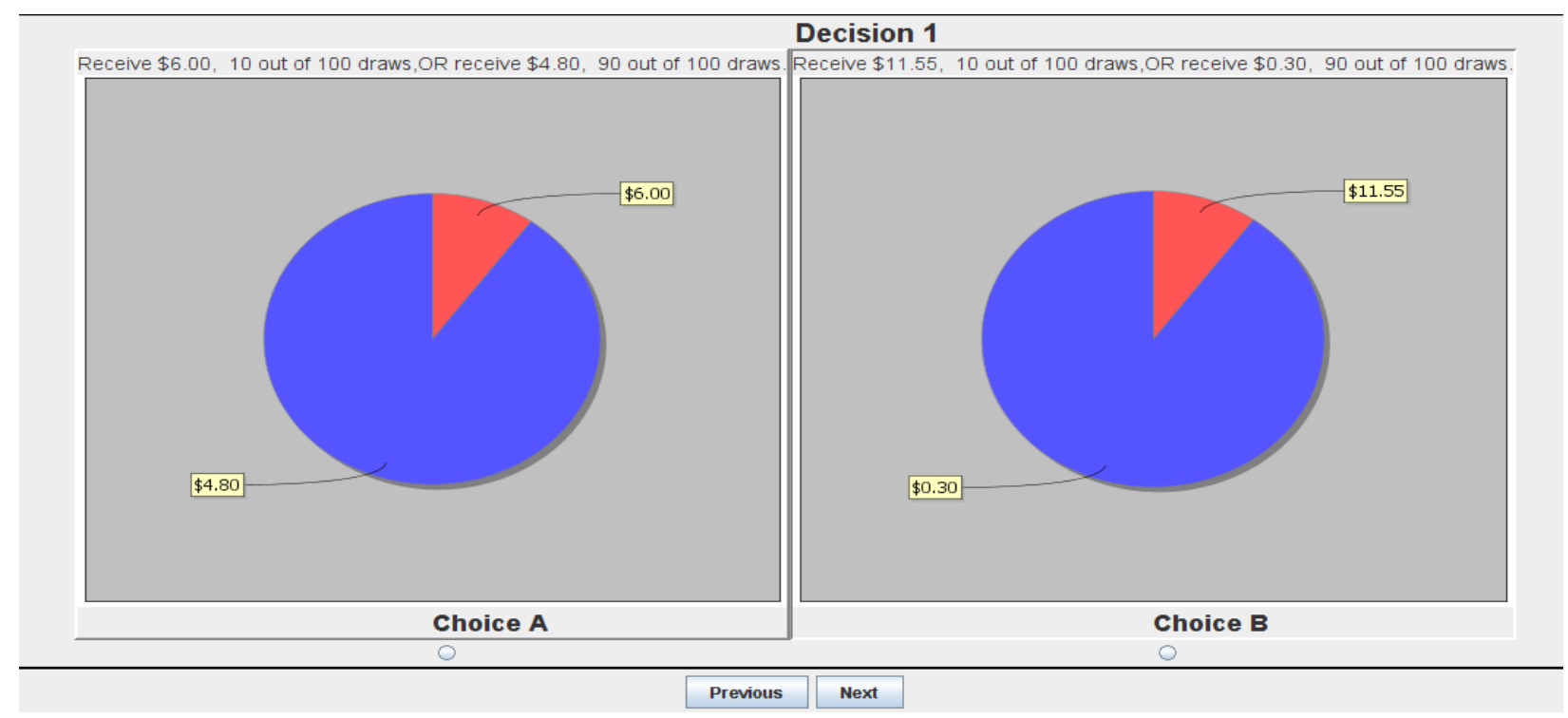

The pie charts help you to visualize your chances of receiving the two amounts presented by each option. When you are ready to make a decision, simply click on the button below the option you wish to choose. Please also circle your choice for each of the 10 decisions on your record sheet. When you are satisfied with your choice, click the Next button to move on to the next decision. You may choose Option A for some decisions and Option B for others and you may change your decisions or make them in any order using the Previous and Next buttons.

When you have completed all 10 choices, and you are satisfied with those choices you will need to click the Confirm button that appears following decision 10. The program will check that you have made all 10 decisions; if not, you will need to go back to any incomplete decisions and complete those decisions which you can do using the Previous button. You can also go back and change any of your decisions prior to clicking the confirm button by using the Previous button.

Once you have made all 10 decisions and clicked the Confirm button, the results screen will tell you the decision number $1,2 \ldots 10$, that was randomly selected by the computer program. Your choice of option A or B for that decision (and that decision only) will then be used to determine your dollar payoff. Specifically, the computer will draw a random number between 1 and 100 (all numbers have an equal chance) and report to you both the random number drawn and the payoff from your option choice.

Your payoff will be added to the amount you have already earned in today's experiment. Please circle the decision that was chosen for payment on your record sheet and write down both the random number drawn by the computer program and the amount you earned from the option you chose for that decision on your record sheet. On the computer monitor, type in your subject ID number, which is the same number used to identify you in the first experiment in today's session. Then click the "Save and Close" button.

Are there any questions before we begin? 
Please do not talk with anyone while these decisions are being made. If you have a question while making decisions, please raise your hand.

Record Sheet

Player ID Number

\begin{tabular}{|c|c|}
\hline & Circle Option Choice \\
\hline Decision 1 & A \\
\hline \multirow{3}{*}{ Decision 2} & Circle Option Choice \\
\hline & A \\
\hline & Circle Option Choice \\
\hline \multirow[t]{2}{*}{ Decision 3} & A \\
\hline & Circle Option Choice \\
\hline \multirow[t]{2}{*}{ Decision 4} & A \\
\hline & Circle Option Choice \\
\hline \multirow[t]{2}{*}{ Decision 5} & A \\
\hline & Circle Option Choice \\
\hline \multirow[t]{2}{*}{ Decision 6} & A \\
\hline & Circle Option Choice \\
\hline \multirow[t]{2}{*}{ Decision 7} & A \\
\hline & Circle Option Choice \\
\hline \multirow[t]{2}{*}{ Decision 8} & A \\
\hline & Circle Option Choice \\
\hline \multirow[t]{2}{*}{ Decision 9} & A \\
\hline & Circle Option Choice \\
\hline Decision 10 & A \\
\hline
\end{tabular}

At the end of this experiment, circle the Decision number selected by the computer program for payment. Write down the random number drawn for the selected decision (between 1 and 100):

Write down your payment earned for this part of the experiment: _\$ 